\title{
Social judgments of sexual behavior and use of HIV pre-exposure prophylaxis
}

\author{
Joel E. Martinez ${ }^{1,2} \&$ Kai J. Jonas ${ }^{3}$
}

${ }^{1}$ Department of Psychology, Princeton University, Princeton, NJ, USA

2 Woodrow Wilson School of Public and International Affairs, Princeton University, Princeton, NJ, USA

${ }^{3}$ Department of Work and Social Psychology, Maastricht University, The Netherlands

Word count: 6613

\section{Correspondence should be addressed to:}

Joel Eduardo Martinez

joeledmartinez@gmail.com

or

Kai J. Jonas

kai.jonas@maastrichtuniversity.nl

Note: This manuscript has been accepted at Social Cognition. 
RUNNING HEAD: Social judgments of sexual behavior and PrEP

\begin{abstract}
Bio-medical HIV pre-exposure prophylaxis (PrEP) can drastically decrease the transmission of HIV between sexual partners. However, peer evaluations may worry men who have sex with men (MSM) that are considering or taking PrEP. We used a trait transference paradigm to characterize attitudes towards PrEP users, their sexual behavior, and transference effects on their social network. We recruited 339 men across nine U.S. cities from advertisements on a phone dating application. They judged vignettes about MSM and associated friends on their trustworthiness and responsibility, with the main character described as having frequently changing partners (FCP) or monogamous, and taking PrEP or not. We found PrEP praise within our U.S. sample, especially when evaluating responsibility, while FCP behavior was negatively evaluated. Minimal transference effects suggested judgments about sex-related actions anchor to the actor. These insights identify contextual boundaries of associative cognition and can inform interventions hoping to improve PrEP acceptance and uptake.
\end{abstract}

Key words: PrEP, HIV Prevention, Social Judgment, Relationships 
RUNNING HEAD: Social judgments of sexual behavior and PrEP

In 2012, the US Food and Drug Administration approved the drug Truvada $₫$ as a biomedical HIV pre-exposure prophylaxis (PrEP) for HIV negative individuals. PrEP involves a daily antiretroviral oral pill, and daily or event-based PrEP regimen has been shown to be an effective strategy for reducing HIV transmissions (Anderson et al., 2012; Donnell et al., 2014; Jiang et al., 2014). Surprisingly, there has been a slow uptake of this medication by the target population, men who have sex with men (MSM) (Kirby \& Thornber-Dunwell, 2014), spurring a need to identify possible obstacles. The social consequences that arise from an individual's sexual conduct and their choice to take PrEP could deter MSM from taking an effective sexual health medication like PrEP, prevent them from seeking information, or from building relationships within their peer community. Therefore, we focus on mapping the social perceptions of PrEP users and how these perceptions may generalize to their close friends to better characterize one such barrier: PrEP stigma.

Practical and social barriers to PrEP use

Despite high prevention efficacy and effectiveness, there are practical barriers to PrEP uptake: Difficulty adhering to a daily regimen (Grant \& Marshall, 2013; PérezFigueroa, Kapadia, Barton, Eddy, \& Halkitis, 2015), cost and lack of insurance coverage (Auerbach, Kinsky, Brown, \& Charles, 2015; Grant \& Marshall, 2013; Peng et al., 2012; Pérez-Figueroa et al., 2015), possible side effects (Auerbach et al., 2015; Grant \& Marshall, 2013; Pérez-Figueroa et al., 2015), lack of exposure to PrEP information (Pérez-Figueroa et al., 2015), and lack of access to related sexual health resources (e.g., condoms or HIV tests) (Ayala et al., 2013). 
RUNNING HEAD: Social judgments of sexual behavior and PrEP

Next to these hurdles, there is increasing evidence that social evaluations may also play a crucial role in PrEP uptake (Ayala et al., 2013; Calabrese \& Underhill, 2015; Gallagher et al., 2014; Haire, 2015; Liu et al., 2014). For example, a study with MSM reported that perceived PrEP stigma (i.e., the assumption that the use of PrEP fosters risky sexual behavior) was negatively associated with PrEP acceptance (Ayala et al., 2013). There is even a recent linguistic trend that specifically labels PrEP users as “Truvada Whores"a (An et al., 2014; Calabrese \& Underhill, 2015; Duran, 2012; Sobo, 2012), a targeted variant of the pejorative use of the term "whore" or "slut" known to generally occur between MSM (McDavitt \& Mutchler, 2014). As such, one consideration for an individual thinking about starting PrEP may be how others will perceive them and the consequences of those perceptions. For example, knowledge of someone's PrEP use influences decisions about potentially having sex with that person (i.e., PrEP sorting) among MSM (Martinez \& Jonas, 2019). This social component invites the possibility that specific evaluative dimensions underlie PrEP judgments, that PrEP judgments may operate at a relational level, and that this relational aspect may activate associative cognitive mechanisms that exacerbate consequences of PrEP judgments.

\section{Evaluative underpinnings of PrEP}

PrEP is not only relevant for the individual, but it also impacts romantic relationship and dating contexts. The documented stigma surrounding PrEP suggests PrEP users are devalued on foundational dimensions of social stereotyping, warmth (or morality) and competence (or responsibility) (Cuddy, Fiske, \& Glick, 2008; Fiske, Cuddy, \& Glick,

\footnotetext{
a It should be noted that "Truvada Whore" has recently been reclaimed by PrEP activists through the use of the hash tag \#TruvadaWhore on social media to instigate discourse over PrEP use and stigmatization (Baker, 2015; Glazek, 2016), similar to the reclaiming of "queer" (Brontsema, 2004).
} 
RUNNING HEAD: Social judgments of sexual behavior and PrEP

2007; Rosenberg, Nelson, Vivekananthan, \& Johnstone, 1968; Wojciszke, 2005) that have been shown to play a role in relationship and dating contexts (Eckes, 2002). PrEP is thought to increase the number of sexual partners (Haire, 2015), which is perceived as immoral behavior where targets are held responsible for the negative outcomes of their sexual behavior (McDavitt \& Mutchler, 2014; Smit et al., 2011). PrEP can also be perceived as an alternative to condoms that increases sexual risk taking, contradictory to the goal of sexual safety. PrEP users may therefore be seen as irresponsible, since they are assumed to take more sexual risks at their peril, and untrustworthy under the assumption they frequently change partners (FCP) and may not be faithful to a main partner. Therefore, we hypothesize that FCP behavior should be judged as less responsible and trustworthy in individuals and, if the "Truvada Whore" phenomena can be empirically captured, we expect PrEP use to also lead to similar negative evaluations.

\section{Generalized attitudes: PrEP is Relational}

While research has focused on the negative effects of PrEP or sexual judgments on the targeted individual (Brown \& Trevethan, 2010) or the group as a whole (Quirk, Wolitski, Parsons, Gómez, \& Men, 2006; Smit et al., 2011), less is known about its more relational effects. Following work on generalized attitudes, a further consideration involves how this decision subsequently affects how their friends are perceived, potentially increasing the social cost of PrEP use. PrEP is an HIV prevention tool that has become part of a discourse surrounding MSM and the LGBTQI community indicated for example by the rise in PrEP activism (Reynolds, 2014), articles in popular media discussing “Truvada Whores” (Baker, 2015; Duran, 2012; Glazek, 2016; Sobo, 2012) and

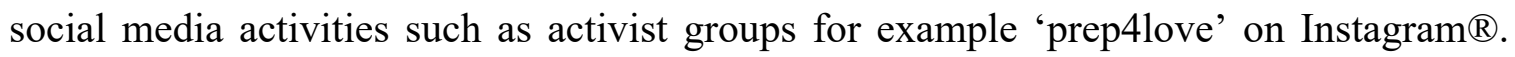


RUNNING HEAD: Social judgments of sexual behavior and PrEP

Geo-spatial dating apps used by MSM serve an important impression formation function, too (Blackwell, Birnholtz, \& Abbott, 2014). PrEP discourse and attitudes therefore have the potential to shape and be shaped by associative processes. Given that friendships are a highly important bond for MSM (Gillespie, Frederick, Harari, \& Grov, 2015; Weston, 1991), we hypothesized that social judgments of PrEP users and their sexual behavior might also generalize and target their associated friends constituting an additional social barrier.

Generalization represents the phenomenon whereby an attitude or behavior towards a target is transferred and is triggered by or affects a related secondary target (De Houwer, Thomas, \& Baeyens, 2001; Glaser et al., 2015). For example, if one associates a liked or disliked object with a neutral object, the neutral object takes on the valence of the associated object (Hofmann, De Houwer, Perugini, Baeyens, \& Crombez, 2010; Wimmer \& Shohamy, 2012). Similarly, the evaluation of an individual can transfer and affect perception of and behavior towards individuals related through co-occurrence (Walther, 2002), meaningful relationships (Martinez, Mack, Gelman, \& Preston, 2016; Przybylinski \& Andersen, 2012), group membership (Crawford, Sherman, \& Hamilton, 2002; Gawronski, Geschke, \& Banse, 2003; Ranganath \& Nosek, 2008; Ratliff \& Nosek, 2011; Stark, Flache, \& Veenstra, 2013), physical similarity (Gawronski \& Quinn, 2013; Verosky \& Todorov, 2013), balanced attentional processing across targets (Uleman, Adil Saribay, \& Gonzalez, 2008), and even spatial proximity (Hebl \& Mannix, 2003).

Generalization is supported by associative memory mechanisms which are thought to bind related elements of experience in an associative network (Gawronski \& Bodenhausen, 2011; Schlichting \& Preston, 2015; Zeithamova, Dominick, \& Preston, 
RUNNING HEAD: Social judgments of sexual behavior and PrEP

2012) or relational schema (Andersen, Tuskeviciute, \& Przybylinski, 2017). Over experience the network links are strengthened and the activation of one element can activate connected elements which can have the consequence of diffusing information or evaluation to those elements, such as valence (Martinez et al., 2016; Wimmer \& Shohamy, 2012). Attitude generalization could therefore prove to be a powerful mechanism by which PrEP judgments affect multiple individuals across MSM social relationships.

\section{Current Research}

To interrogate the extent to which the "Truvada Whore" phenomenon is reflected in social judgments of MSM who take PrEP and their friends (e.g., negative responsible and trustworthy evaluations), we employed a vignette-rating paradigm. In line with the sparse information approach that would be encountered in online dating contexts, we created a survey containing multiple short vignettes with the goal of examining social judgments of PrEP and sexual behavior and how they might affect multiple individuals. The vignettes portrayed a male main character using PrEP (or not) and having sexual relations within a monogamous relationship or FCP. These four conditions represent examples of possible experiences in the world: men who engage in FCP behavior and take PrEP (e.g., individuals with FCP behavior or PrEP advocates who promote sex positivity) or not (e.g., men who use alternative methods of safety like condoms or individuals showing high-risk sexual behavior) and monogamous men who take PrEP (e.g., serodiscordant couples or men in relationships who take a safety-first approach or men with clinically relevant HIV anxiety) or not (e.g., men who rely on condoms or on the exclusivity of monogamy). 
RUNNING HEAD: Social judgments of sexual behavior and PrEP

Moreover, these vignettes also mentioned a long-term platonic friend in each of the main character's life. The critical question was how the participants not only judged the main character, but also their friends. Judgments of the main characters help characterize how the combination of PrEP and sexual behavior is perceived in our sample of MSM while the friends' judgments provide insight on whether judgments of sexual health and behavior can transfer across social relationships and affect evaluations through associative mechanisms.

\section{Method}

\section{Participants and Design}

The design was a 2(PrEP vs NoPrEP) x 2(FCP vs. monogamous) within-subjects design.

Using a convenience sampling approach 450 participants were recruited from push message advertising (in the period of July 11 to July 18, 2015) on an online smart phone geospatial dating application geared towards MSM. The application is used by many MSM as a way to find sexual partners and therefore targets a very specific population that represents the ideal market for PrEP. Due to the limited time window and convenience sampling technique, we aimed at obtaining as many responses as we could. The advertisement provided a chance to win one of $20 \$ 35$ gift cards or an Apple watch. The message was spread across two days within a week span and targeted men across nine geographically separated U.S. cities: Austin, TX, Columbus, OH, Hartford, CT, Miami, FL, Pittsburgh, PA, Sacramento, CA, San Diego, CA, Seattle, WA, and St. Louis, MO. 
RUNNING HEAD: Social judgments of sexual behavior and PrEP

All participants were consented in accordance to the University of Amsterdam's IRB (2015 SP-4584). The survey was offered in English and Spanish. After exclusions for incomplete surveys $(n=103)$ and multiple entries $(n=8)$ the final eligible sample included 339 men (ages 18-81, mean age $=32.6$ ). The racio-ethnic distribution consisted of 52.5\% Caucasian, 25.4\% Latino, 7.7\% Asian, 7.4\% African American, .6\% Pacific Islander, .3\% Native American Indian, and 6.2\% Other. Additionally, 258 of the men were HIV negative and not taking PrEP, 31 were HIV negative and taking PrEP, 25 were living with HIV, 23 did not know, and 2 declined to reveal their serostatus.

\section{Vignettes}

The vignettes used in this study were the same vignettes used in Martinez \& Jonas (2018). They contained a main character who was differentiated by Sexual behavior (either FCP or monogamous) and by PrEP use (taking PrEP: PrEP, or not: NoPrEP), and a description of an activity that related the main character with a good platonic male friend (see Supplementary Table A). There were two vignettes that represented each combination of the Sexual behavior and PrEP use conditions resulting in eight vignettes total that each participant read. Each story indicated whether the main characters used PrEP or not. The FCP characters were portrayed as regularly partaking in what can be considered "risky" sexual encounters with multiple partners in a variety of sexual settings (e.g., " $V$ and his good friend D host a movie night every weekend. V uses Truvada and loves to sleep with as many bareback gays at the local bath house"). The monogamous men were portrayed as being sexual with their main partner only (e.g., " $T$ and his boyfriend fuck raw and take Truvada daily for safety. F, T's good friend, often goes on road trips with him"). Presentation of the vignettes was randomized across participants. 
RUNNING HEAD: Social judgments of sexual behavior and PrEP

The descriptions explicitly noted that none of the main characters used condoms in any condition. Their sexual position preference was also left ambiguous. The friend activities depicted one of four domains (food, leisure, travel, workout) and were counterbalanced across PrEP use. The names of the characters were designated by a single capital letter and there were no overlapping letter pairs or any letter repetition. Two decisions should be noted in the context of the vignettes. First, some of the vignettes contained very explicit language. The language was chosen for three reasons: it is commonly understood and used among MSM when discussing condomless sexual acts and it provided variety in describing the same kind of act to keep the task engaging. Moreover, using more abstract, scientific medicalized language, e.g. "condomless anal intercourse" instead of "fuck raw" is often perceived by the target group as distancing and even discriminatory (Spieldenner, 2016). The second decision was to implement a vast difference in the described activities of the main actor and the friends. This difference can be considered a conservative test of the transfer effect. If the friend was also directly associated with the sexual activities of the main character, we would not be able to disentangle whether an evaluative transfer occurred between friend pairs or if the sexual activity itself drove the evaluations of the friend irrespective of the main character.

\section{Measures}

Judgments were made about the trustworthiness and responsibility of the characters and, as a manipulation check of perceptions of FCP, how "slutty" they were. While "slut" is commonly used in the community and was the actual phrasing of the measure, for this manuscript we will refer to this as measuring perceptions of FCP. The measures included a five-point scale where a 5 represented a very trustworthy, 
RUNNING HEAD: Social judgments of sexual behavior and PrEP

responsible, or FCP rating and a 1 reflected a very untrustworthy, very irresponsible, not FCP rating. Ratings of the characters were completed immediately after reading each scenario at the participant's leisure and the survey allowed pausing (median $=17$ minutes, mean $=62$ mins $)$.

This task was part of a larger survey to characterize MSM PrEP users in the United States across many dimensions: legal, economic, psycho-medical, and social. Those measures are beyond the scope of this paper. Additional questions about affiliative intent were also asked about the characters in these vignettes, however these measures are reported in another paper (Martinez \& Jonas, 2019). Thus, we report all pertinent measures, manipulations, and exclusions in this study and the full sample was collected before data analysis.

Data analysis plan

Main analyses were performed with a subset of the sample $(n=258)$ that declared themselves as HIV negative and not currently taking PrEP, unless otherwise noted. This was the largest group in our sample and the most relevant population as they are the targets for PrEP use, but also for PrEP stigma effects. In order to provide careful inferences of transference, we report two tests. The first examines the correlation between participants' ratings of the main character and the friend in each condition. First, each participant's ratings were averaged across the two vignette per condition to obtain one score per participant for the main and friend characters. This procedure fulfills the correlation requirement of independence of observations. Then, between-participant correlations were calculated per condition and per trait rating. Such a correlation could suggest that individual participants generalized their judgments across friend pairs. 
RUNNING HEAD: Social judgments of sexual behavior and PrEP

The second test of transference focuses on aggregate-level transference. To do this, responsibility and trustworthy ratings were independently predicted by an interaction between PrEP, Sexual Behavior, and Character. The PrEP x Sexual behavior interaction maps judgments of different sexual and health behaviors. The character moderator tests the magnitude of transference by assessing if effect size differed between main and friend characters.

For specific tests of the "Truvada Whore" hypotheses that characterize the actual judgments given to the characters, we then assess the PrEP x Sexual behavior interaction from the same model separately for the main and friend characters.

For interested readers, exploratory moderator analyses that examined group differences in these ratings due to discriminatory attitudes, interest in taking PrEP, or sexual health status can be found in the supplementary material (Figure S1 and Tables D, E, F).

Regression analyses were conducted using mixed-effects models in the R package "Ime4" version 1.1-11 with participants and vignettes as crossed random effects to control and account for multiple sources of variation and dependencies in the data (Baayen, Davidson, \& Bates, 2008; Judd, Westfall, \& Kenny, 2012). The models allowed within-subject slopes to vary by participant and varying intercepts by the vignettes, with the goal of using the maximal random effect structure allowed by the data (Barr, 2013; Barr, Levy, Scheepers, \& Tily, 2013). The maximal model did not converge for the responsibility ratings, however, removing the highest order interaction helped convergence. Planned comparisons and confidence intervals were computed using Satterthwaite approximated degrees of freedom with the Least-Squares Means 
RUNNING HEAD: Social judgments of sexual behavior and PrEP

("lsmeans") package in R version 2.25 (Lenth \& Hervé, 2015). Effect sizes (d) were calculated by dividing betas by the standard deviation of the residual variance of the models (Rouder, Morey, Speckman, \& Province, 2012). For raw means and standard deviations, see Supplementary Table B and D. The data and scripts can be found at the following Open Science Framework archive: https://osf.io/3mf75/.

For complete regression tables of the main analyses (Supplementary Table C), the interest and attitude moderators (Supplementary Table E), and the HIV and PrEP status moderator (Supplementary Table F), see the corresponding supplementary tables.

\section{Power analysis}

While post-hoc power analyses are often considered to be uninformative (Hoenig \& Heisey, 2001), we provide compromised power analyses, each using 100 Monte Carlo simulations of the mixed regression models using the "simr" $\mathrm{R}$ package (Green \& Macleod, 2016). We searched through a limited range of effect sizes for the minimum Sexual behavior x PrEP use interaction effect we could detect with around $80 \%$ power given our sample size of the main analyses, $\mathrm{n}=258$, and an alpha of .05 . The smallest effect we could detect for the responsibility ratings at $79 \%$ power was $d=.358$, a little smaller than our observed effect, $\mathrm{d}=.38$. For trustworthiness ratings, with $85 \%$ power the effect would have needed to be $\mathrm{d}=.43$ to be detected, much larger than our observed effect, $\mathrm{d}=.06$.

\section{Results}

Trait correlations 
RUNNING HEAD: Social judgments of sexual behavior and PrEP

Trustworthiness and responsibility were highly correlated for the main character, average $r=.79$, and the friend, average $r=.89^{\mathrm{b}}$, however the two measures are reported separately as they are conceptually distinct. While FCP mainly served as a manipulation check, see below, it was negatively correlated with trustworthiness, average $r=-.49$, and responsibility, average $r=-.45$, for the main characters. The same occurred with trustworthiness, average $r=-.43$, and responsibility, average $r=-.46$, of the friend characters.

\section{Promiscuity manipulation check}

To examine whether the promiscuity of the characters in our stories were perceived as intended, we ran mixed models to predict the FCP measure from the interaction of sexual behavior and PrEP use separately within the main character and the friend ratings. Only the sexual behavior, specifically FCP, of the main character predicted $\mathrm{FCP}$ ratings, $\mathrm{b}=1.41, \mathrm{~d}=2.16, \mathrm{SE}=.075, \mathrm{t}(38)=18.64, \mathrm{p}<.0001$, with no effects of PrEP use or the interaction, ps $>.311$. Furthermore, there were no effects in the FCP ratings of the friends, ps $>.32$. As such, not only did this measure serve as a manipulation check that the promiscuity of the characters described in the vignettes was perceived as intended, it also suggests that PrEP use itself may not be directly related to perceptions of FCP. This measure was not analyzed further.

\section{Perceptions of Main Characters}

\footnotetext{
$\mathrm{b}$ We conducted an exploratory factor analysis (PCA) with varimax rotation, the model extracted three factors with an eigenvalue $>1.6$ and explained 60.5 percent of the variance. Factor 1 included all trustworthy and responsibility rating for the FCP main character (factor loadings $<$ .77 and $>.59$ ). The second and third factor distinguished between monogamous main characters taking PrEP (factor loadings $<.81$ and $>.72$ ) or not (factor loadings $<.75$ and $>.67$ ). A two factor solution integrated the monogamous main character into one factor (factor loadings $<.75$ and $>.60)$.
} 
RUNNING HEAD: Social judgments of sexual behavior and PrEP

This section focuses on characterizing judgments of the main characters. A strong interpretation of the "Truvada Whore" hypothesis predicts two simple effects: that participants should rate the FCP and PrEP using characters as less responsible or trustworthy than their monogamous and NoPrEP counterparts. An interaction would instead suggest that the phenomenon is more nuanced: that evaluations of PrEP use will depend on the associated sexual behavior.

The responsibility ratings exhibited an interaction between Sexual behavior and PrEP use, $\mathrm{b}=.283, \mathrm{~d}=.43, \mathrm{SE}=.067,95 \% \mathrm{CI}[.15, .42], \mathrm{t}(33.04)=4.23, \mathrm{p}=.0002$ Figure 1A. In the monogamous condition, NoPrEP characters were rated as less responsible than PrEP characters, $\mathrm{b}=-.876, \mathrm{~d}=1.33, \mathrm{SE}=.063,95 \% \mathrm{CI}[-1.0,-.75]$, $\mathrm{t}(81.69)=-13.98, \mathrm{p}<.0001$. The FCP condition showed the same pattern but the difference was smaller, $\mathrm{b}=-.593, \mathrm{~d}=.902, \mathrm{SE}=.062,95 \% \mathrm{CI}[-.71,-.47], \mathrm{t}(78.44)=-$ 9.60, $\mathrm{p}<.0001$. FCP characters were judged as less responsible than monogamous characters, $\mathrm{b}=-1.53, \mathrm{~d}=2.3, \mathrm{SE}=.07,95 \% \mathrm{CI}[-1.7,-1.4], \mathrm{t}(109.74)=-21.86, \mathrm{p}<.0001$.

For trustworthiness, there was no interaction between Sexual Behavior and PrEP use, $\mathrm{b}=.047, \mathrm{~d}=.07, \mathrm{SE}=.09,95 \% \mathrm{CI}[-.13, .23], \mathrm{t}(21.04)=.543, \mathrm{p}=.593$; Figure $1 \mathrm{~B}$. NoPrEP characters were rated as less trustworthy than PrEP characters, $b=-.403, d=$ $.64, \mathrm{SE}=.07,95 \% \mathrm{CI}[-.54,-.27], \mathrm{t}(28.29)=-6.15, \mathrm{p}<.0001$. FCP characters were rated as less trustworthy than monogamous characters, $b=-.986, d=1.56, \mathrm{SE}=.08,95 \% \mathrm{CI}[-$ $1.5,-.83], \mathrm{t}(55.99)=-12.40, \mathrm{p}<.0001$.

Contrary to the "Truvada Whore" hypothesis whereby PrEP itself is stigmatized, PrEP use boosted the perceived responsibility of monogamous characters more than FCP ones and thus the combination of monogamy and PrEP use was judged positively. 
Partially in support of the hypothesis, evaluations of PrEP use were negative when paired with FCP behavior, suggesting it is the associated sexual behavior that drives PrEP judgments. It is worth nothing that even in the FCP condition, PrEP use was seen as more responsible than NoPrEP. The trustworthy ratings reflected the same pattern, but only through simple effects where FCP and NoPrEP were judged as less trustworthy suggesting a possible asymmetry in how the domains are related to PrEP judgments.

A

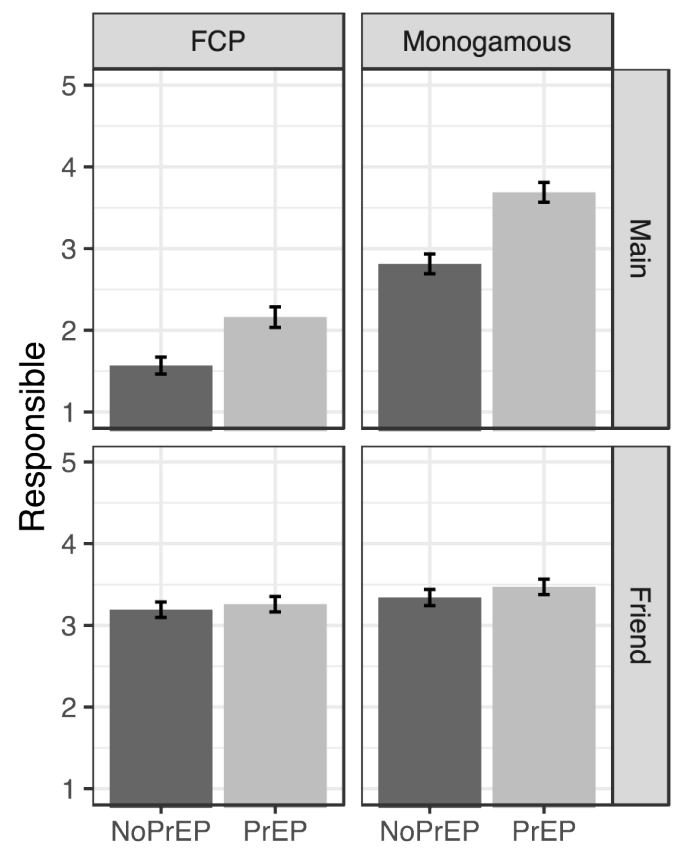

B

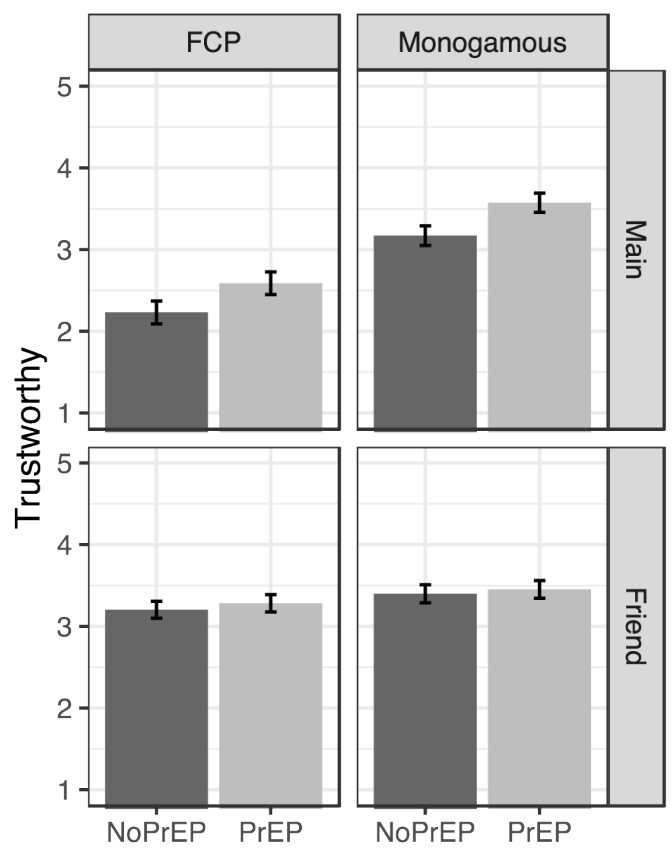

Figure 1: Judgment ratings. A) Average responsible ratings for the main and friend characters who were monogamous or frequently changing partners ("FCP") and taking PrEP ("PrEP") or not ("NoPrEP"). B) Average trustworthy ratings for the main and friend characters. Error bars represent $95 \%$ confidence intervals.

Generalization of Judgments to the Friend Characters 
RUNNING HEAD: Social judgments of sexual behavior and PrEP

It was hypothesized that attitude generalization might influence the rating of an affiliated other, and thus the pattern of judgments for the associated friend should be similar to the main character. Likewise, generalization may not operate in this context and would predict non-congruent patterns between judgments of the friend and main character. Here, we report two tests of transference that focus on the question of generalization. The first is a regression approach where similar aggregate-level pattern and magnitude of characterizations of the friends as the main characters would be indicative of generalization. The second is a correlation approach where higher correlations between participant-level ratings of the main and friend characters could be indicative of generalization.

Regression Analyses

To examine aggregate-level transference, whether the magnitude of social judgments weakened as, or if, they transferred from main character to their friend, this analysis directly compared the ratings for the main character and the friend. There was a three-way interaction between Character, Sexual behavior, and PrEP use for the responsibility ratings, $\mathrm{b}=.22, \mathrm{~d}=.34, \mathrm{SE}=.082,95 \% \mathrm{CI}[.06, .38], \mathrm{t}(2830.93)=2.70, \mathrm{p}$ $=.007$, but not for trustworthiness, $\mathrm{b}=.07, \mathrm{~d}=.12, \mathrm{SE}=.084,95 \% \mathrm{CI}[-.09, .24]$, $\mathrm{t}(576.59)=.878, \mathrm{p}=.380$. The two-way interaction between Sexual Behavior and PrEP use that was significant in the main characters' ratings was not significant in the friends' responsibility ratings, $\mathrm{b}=.062, \mathrm{~d}=.09, \mathrm{SE}=.067,95 \% \mathrm{CI}[-.07, .20], \mathrm{t}(33.04)=.928, \mathrm{p}=$ .360; Figure 1A. Friends of NoPrEP users were only qualitatively rated as less responsible than PrEP friends, $\mathrm{b}=-.07, \mathrm{~d}=.10, \mathrm{SE}=.04,95 \% \mathrm{CI}[-.15, .02], \mathrm{t}(26.17)=-$ $1.53, \mathrm{p}=.138$. Friends of FCP characters were rated as less responsible than friends of monogamous characters, $\mathrm{b}=-.211, \mathrm{~d}=.32, \mathrm{SE}=.05,95 \% \mathrm{CI}[-.31,-.11], \mathrm{t}(33.91)=-$ 
RUNNING HEAD: Social judgments of sexual behavior and PrEP

4.42, $\mathrm{p}=.0001$. The sizes of these simple effects were also smaller than in the main characters' ratings $(d s>.80, p s<.0001)$.

The two-way interaction between Sexual Behavior and PrEP use was also not significant in the trustworthiness judgments, $\mathrm{b}=.027, \mathrm{~d}=.04, \mathrm{SE}=.08,95 \% \mathrm{CI}[-.19$, $.14], \mathrm{t}(14.34)=.351, \mathrm{p}=.731$; Figure 1B. Friends of PrEP users were not rated as significantly more trustworthy than friends of NoPrEP, $b=.05, d=.08, \mathrm{SE}=.06,95 \%$ $\mathrm{CI}[-.07, .17], \mathrm{t}(14.91)=0.95, \mathrm{p}=.358$. Friends of FCP characters were rated as less trustworthy than friends of monogamous characters, $\mathrm{b}=-.169, \mathrm{~d}=.27, \mathrm{SE}=.06,95 \%$ $\mathrm{CI}[-.29,-.05], \mathrm{t}(15.89)=-3.00, \mathrm{p}=.009$. The sizes of these effects were moderated by character: Character x Sexual behavior, $\mathrm{b}=.82, \mathrm{~d}=1.29, \mathrm{SE}=.073,95 \% \mathrm{CI}[.68, .96]$, $\mathrm{t}(337.45)=11.28, \mathrm{p}<.0001$, and Character $x$ PrEP use, $\mathrm{b}=.35, \mathrm{~d}=.55, \mathrm{SE}=.064,95 \%$ $\mathrm{CI}[.23, .46], \mathrm{t}(400.30)=5.52, \mathrm{p}<.0001$. In both cases, the main character showed larger simple effects of PrEP use and Sexual behavior than the friends.

Overall, the friend character was evaluated negatively if they were friends with FCP characters (or evaluated better if friends with monogamous characters). The PrEP use of the main character had a minor effect on judgments of the friends. The main characters exhibited larger interaction and simple effects than the friends in the responsibility ratings and larger simple effects than the friends in trustworthiness ratings, meaning that judgments primarily anchored to the main character. This pattern of results can be attributed to a weakening of judgment transference at the aggregate-level.

\section{Correlation analyses}

As a participant-level test of transference, we report correlations between judgments of the main characters and friends in each condition. For both responsibility and trustworthy ratings, judgments of the main characters showed moderately sized 
RUNNING HEAD: Social judgments of sexual behavior and PrEP

correlations with judgments of the friends in each condition (Figure 2 A $\&$ 2B). These bivariate relationships provide some evidence that judgments of the main characters generalized and affected the associated friend. However, as can be seen from the plots, these correlations require some care in interpretation.

First, each condition showed varying levels of ambivalence. This means that while there were some participants that rated both characters positively or negatively in every condition, the amount of either varied by condition. For example, the correlations in the monogamous conditions were mainly driven by the upper-right quadrant of the plot (mainly positive ratings), whereas other conditions' correlations were driven by upper or lower left quadrants (a mix of positive and negative ratings across characters). Thus, the meanings of the correlations differ greatly as they are anchored on the mean tendency of each condition. Second, the bulk of friend ratings at every level of the main character's ratings hovered around the middle of the scale (3): out of 258 participants, the friends were rated a " 3 " by 132 to 156 participants across conditions in the responsibility ratings and by 135 to 161 participants in the trustworthy ratings. While some participants may be generalizing their initial judgments, most are not. 
A

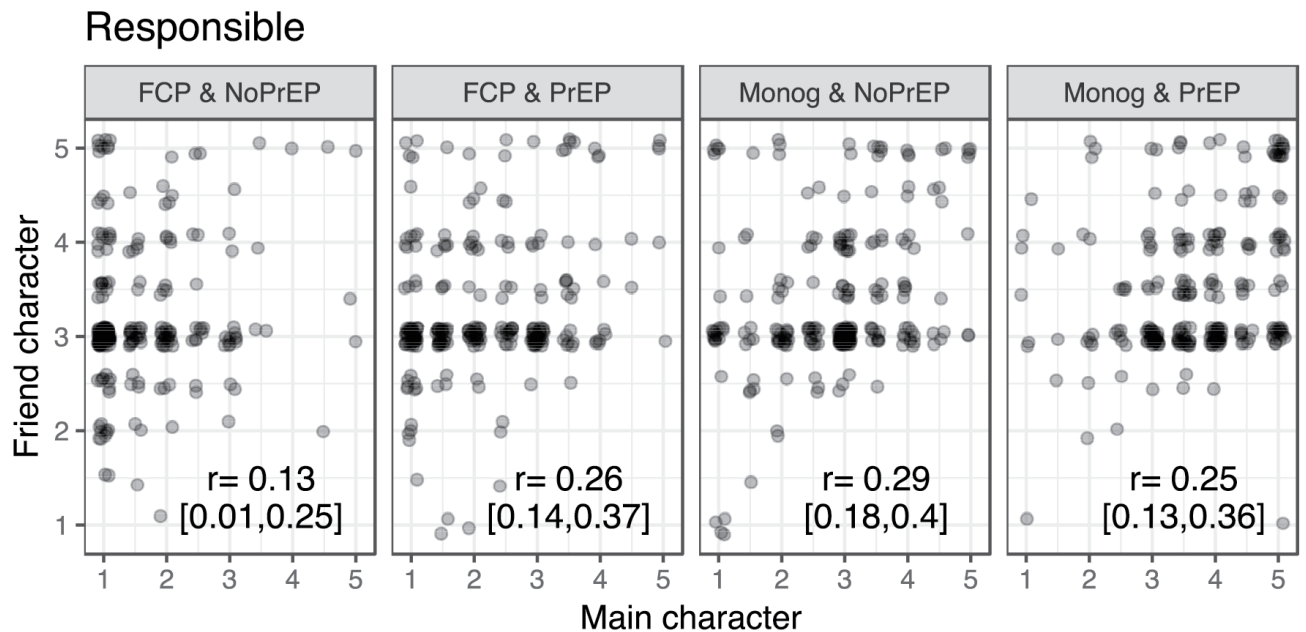

B

Trustworthy

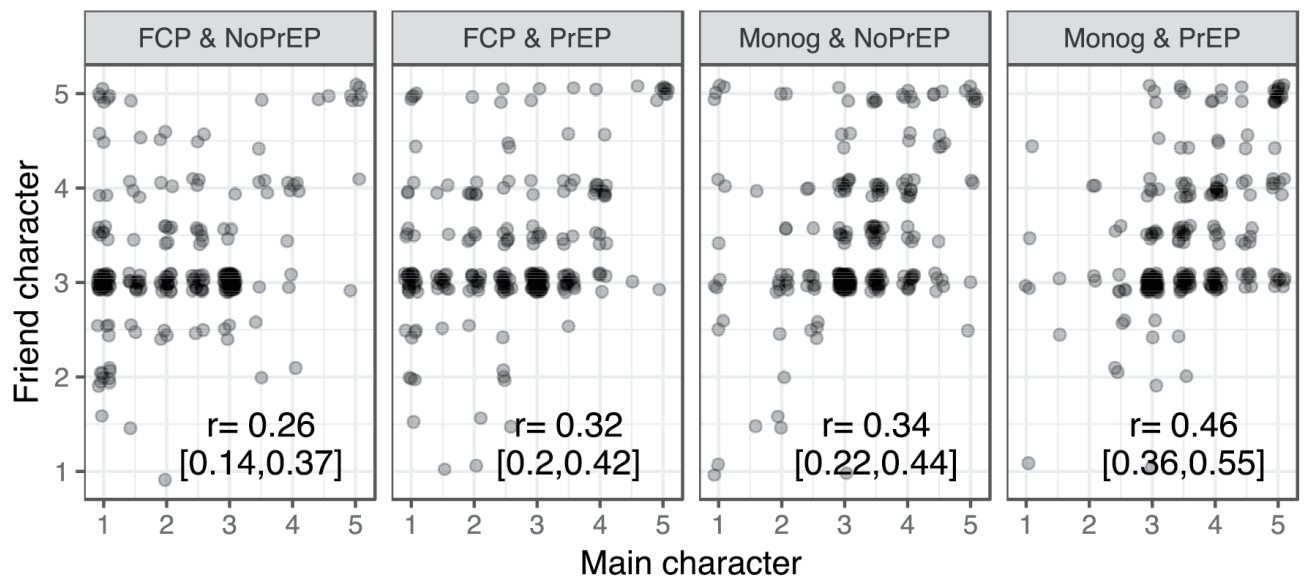

Figure 2. Correlations between main and friend judgments. A) Scatterplot of average responsibility ratings given to the main characters and associated friends per participant. B) Scatterplot of trustworthy ratings. Points are jittered to show density of data. Correlation values are provided along with $95 \%$ CIs in square brackets. FCP $=$ frequently changing partners, Monog = monogamous.

Overall, the transference analyses revealed that social judgments were largest in magnitude for the main character and greatly weakened if and when they transferred to 
RUNNING HEAD: Social judgments of sexual behavior and PrEP

the friend. Any forms of transference in the participant-level correlations were reflected as a weak generalization in the aggregate. This implies that while there were some individuals whom exhibited a link between their judgments of the main and friend characters, there were more that judged the character pairs differently.

\section{Discussion}

Increasingly, there are calls to take socio-sexual attitudes and context into account to provide a richer picture of potential barriers of PrEP uptake and its consequences for prevention efficacy (Auerbach \& Hoppe, 2015; Calabrese \& Underhill, 2015; Haire, 2015). Among social-media-using MSM, our findings provide empirical evidence that responsibility and trustworthiness are integral domains that constitute attitudes towards PrEP (non) users with varying types of sexual behavior. Contrary to PrEP stigma, we found that participants rated PrEP use and monogamous sexual behavior as more trustworthy and responsible than FCP and not using PrEP. However, FCP behavior did lead to negative evaluations of PrEP users suggesting associated behaviors drive perceptions of PrEP users. These negative evaluations were strongest among participants who 1) are not currently taking PrEP and HIV negative or who did not know or disclose their status or 2) are not interested in taking PrEP (see supplementary material). The results also showed that attitudes towards a target's FCP behavior did transfer but have a limited effect on associated friends, whereas attitudes based on PrEP use only affected the target individual.

\section{Limited effects of associative trait transfer}

Transference has a nuanced role in the case of PrEP stigma. The correlational analyses indicated that some people do generalize their judgments in ways that follow the 
RUNNING HEAD: Social judgments of sexual behavior and PrEP

mean tendencies. In other words, if a main character was monogamous and taking PrEP, those who generalized tended to give mostly positive evaluations to both characters. This mean tendency was further corroborated by aggregate analyses showing that the sexual behavior of the main character did matter to some degree in rating the friends. However, the correlation analyses also indicated that most individuals did not generalize, but rather unlinked their judgments of the friends from their judgments of the main character. This result was also corroborated in the regression analyses - despite the significant effect of the main character's sexual behavior on their friends' judgments, the transfer severely weakened the effects. Associative transfer was only qualitatively exhibited for judgments of PrEP use.

These results suggest that judgments related to sexual health dominantly affect the targeted individual, with minor effects on whoever is associated with them. This stands in contrast to previous work showing that transference occurs through both significant and mere associations (Martinez et al., 2016; Walther, 2002). Typically, related elements are linked in an associative memory network whereby valence may travel between activated elements (Gawronski \& Bodenhausen, 2011; Schlichting \& Preston, 2015). For example, one may encounter person "A" frequently changing partners and perceive them as negative. That negativity may spread to representations of known friends of A, resulting in also perceiving the friends as negative.

The small transfer effects in these data may signify an important contextual boundary for how relational memory and trait transference manifests in applied situations (Gawronski \& Cesario, 2013). Research on implicit impressions shows that when descriptions of a behavior are accompanied by the actor and a secondary individual, 
RUNNING HEAD: Social judgments of sexual behavior and PrEP

spontaneous trait inferences are mostly bound to the actor due to greater attentional processing (Uleman et al., 2008). However, our task included important social relationships between the two individuals that should increase the chance of transference. More research is needed to examine why transfer was weak such that only a small subset of participants generalized. It is possible that PrEP or sexual judgments do not transfer by association in a sexual health context where onus is primarily placed on an individual's own actions or agency (Smit et al., 2011). In other words, the overweighing of sexual responsibility unto a primary target may limit the spread of their evaluations across associations, especially when both the target and friends are not known well enough to create robust memory links between them (Gawronski \& Bodenhausen, 2011). Other possibilities include the friend being perceived as not sharing the relevant demographics of the main character (e.g., gender, sexuality), attention being dominantly focused on the main character, or maybe unfamiliarity with the targets such that transfer would occur between highly familiar relationships as would be encountered in close friend networks. In any case, our results do suggest that generalization of PrEP stigma may not be as widespread or strong as earlier qualitative work has suggested it to be.

\section{Asymmetry in diagnosticity of social dimensions}

The results show that PrEP and sexual attitudes are indeed related to both trustworthiness and responsibility. The involvement of these two dimensions is consistent with models from social cognition research that state warmth (related to trustworthiness) and competence (related to agency and responsibility) are fundamental facets of social judgments (Cuddy et al., 2008; Fiske et al., 2007; Rosenberg et al., 1968; Wojciszke, 2005). However, it appears that responsibility was the more diagnostic domain for PrEP 
RUNNING HEAD: Social judgments of sexual behavior and PrEP

evaluations than trustworthiness, in line with responsibility shaming identified in HIV and FCP-related stigma (McDavitt \& Mutchler, 2014; Smit et al., 2011). Responsibility ratings showed a greater decline when FCP and/or NoPrEP was involved and a boost in the monogamous PrEP characters not exhibited in the trustworthiness ratings. Moreover, responsibility ratings exhibited demographic group differences that were absent in the trustworthiness ratings (see supplementary materials). This asymmetry might point to an important distinction that participants dominantly see PrEP use as related to making informed risk-reducing decisions more so than just being a good person.

\section{Limitations}

It should be noted that there are specific characteristics associated with this sample. The sample was obtained on a geospatial smartphone application geared towards a very specific cohort of men who are actively seeking mating partners, and who are mostly not in a monogamous relationship. As such, it is currently unclear how our results will generalize across all MSM in the United States. For example, it is possible that judgments of PrEP using characters may differ for individuals who staunchly oppose PrEP as alternatives to condoms (e.g., Addison, 2015; Crary, 2014) or those who do not use online dating applications because they are in strictly monogamous relationships. Given the nature of online samples, the data may only be representative of individuals who self-select into studies. But, at the same time, this characteristic is noteworthy as MSM seeking partners online may have more risky sexual behaviors and also more STIs and HIV infections (Elford, Bolding, \& Sherr, 2001; Mettey, Crosby, DiClemente, \& Holtgrave, 2003; Ogilvie et al., 2008, but see Davis, Hart, Bolding, Sherr, \& Elford, 2013; Horvath, Rosser, \& Remafedi, 2008), which makes them an ideal group for PrEP 
RUNNING HEAD: Social judgments of sexual behavior and PrEP

use. The convenience sample of this study is ethnically diverse. Most likely because we also offered the survey in Spanish, the study obtained a good representation of Latino Americans. Other ethnic groups where unfortunately represented at lower levels which rendered a between ethnicity analysis statistically unstable. Future research should address this shortcoming as ethnicity is shown to be an important factor in PrEP attitudes (Calabrese et al., 2016), and build upon the dating app based sample of this study and include further relevant variables such as sexual position preference which have their own unique relationship to sexual risk.

One possible limitation is that the lack of a "neutral" condition in our design does not disentangle the direction of effects such that it is unclear whether the pattern of results is driven by praise of PrEP use and monogamy or stigmatization of promiscuity. There are normative assumptions made when labeling a form of lived experience as neutral. Our conditions represent a reductive way to examine what we believe are key social factors in many MSM's lives as related to PrEP. Therefore, we emphasize that our results are a snapshot of the evaluative differentiation of these key factors and necessarily capture a mixture of effects. Future studies could focus on isolating these effects, yet it is questionable whether such an endeavor would have implications for improving PrEP interventions or mainly represents a theoretical discussion within lab-based research contexts.

One last limitation concerns the content and language of the vignettes. As a consequence of our binary manipulation of sexual behavior (monogamous or FCP), we presented very limited and non-exhaustive versions of possible behaviors under these labels. As such, care should be taken in interpreting our results such that they do not 
RUNNING HEAD: Social judgments of sexual behavior and PrEP

suggest all forms of frequent partner change will be stigmatized, e.g., consensual nonmonogamy. Instead, they suggest that the very extreme cases we presented, risky sexual acts, are negatively perceived. Relatedly, the extremity of the cases could have led to contrast effects such that our results are driven by social comparisons across vignettes. Moreover, if the results are driven by contrast effects, we believe it does not change the theoretical conclusions, it adds a mechanistic explanation. In fact, it may be more realistic in terms of how social comparisons occur in gay social networks. Moreover, one possible consequence of using explicit language in the vignettes is that problematic language itself may drive valenced evaluations of the characters. This concern would predict that the monogamous PrEP-using characters, for whom the language happened to be the most explicit, would be given the worst evaluations. However, the results show this is not the case, in fact they received the best evaluations, suggesting the specific language was not the main driver of evaluations, the character depictions were.

\section{Big Picture}

The findings describe the judgments of sexually active men from across the U.S. online MSM community. Our approach speaks to the valuable contribution social cognitive paradigms can make in health-related research and application contexts. Insights from this work are highly relevant for practitioners, NGOs, and government agencies interested in developing strategies or interventions to increase PrEP uptake and

promote acceptance of PrEP to a wider target population (Grant et al., 2014; Grov, Whitfield, Rendina, Ventuneac, \& Parsons, 2015; Krakower et al., 2012; Pérez-Figueroa et al., 2015). In fact, our results are good news. Based on our findings, PrEP use by itself was not linked to perceptions of FCP as expected from the "Truvada Whore" 
RUNNING HEAD: Social judgments of sexual behavior and PrEP

phenomenon or the PrEP stigma literature (Ayala et al., 2013; Calabrese \& Underhill, 2015; Gallagher et al., 2014; Haire, 2015; Liu et al., 2014). Instead, the actual sexual behavior of those taking PrEP mattered more in shifting evaluations. PrEP use in the context of a monogamous relationship provided the best social evaluations in this study, whereas evaluations worsened when paired with FCP behavior. Thus, the symbolic link between Truvada ${ }^{\circledR}$ and "whore" may be more of an imaginary hurdle for PrEP uptake, while the associated behavior may be a more realistic one. Interventions should focus on allowing MSM to reflect on the frequency of changing partners or polyamory they want to be associated with (Coelho, 2011). Successful interventions should build on the impressive and responsible self- and other protection measures taken by PrEP users to protect themselves and their sex partners from HIV infections.

This research was an initial attempt at characterizing the interplay of cognitive and social mechanisms on perceptions of PrEP in line with aspects of the biopsychosocial model that emphasizes the necessity of examining the interaction of biological, psychological, and social factors on health (Engel, 1980; Suls \& Rothman, 2004). Our results are an advancement in this direction by linking an important sexual health drug to evaluative dimensions of social cognition and further showing that cognitive transference does not seem to lead to diffused judgments that affect multiple targets in a sexual health context. The latter emphasizes the powerful weighting of an actor's own behavior and sheds light on the limits of social cognitive mechanisms outside lab contexts and a reassurance that there may not be an extended social cost to PrEP use. However, to fully engage the scope and potential of the model for PrEP, further research should take an integrated approach to how social judgments relate to the actual choice to begin PrEP 
RUNNING HEAD: Social judgments of sexual behavior and PrEP

regiments and partner selection, subsequent medical and health consequences, and the syndemic and cultural contexts in which these decisions are made (Halkitis, 2010; Halkitis, Wolitski, \& Millett, 2013). 
RUNNING HEAD: Social judgments of sexual behavior and PrEP

\section{References}

Addison, B. (2015). Larry Kramer, Truvada Whores and the angry divide between two generations. Retrieved from HIV Equal website: http://www.hivequal.org/hivequal-online/larry-kramer-truvada-whores-and-the-angry-divide-between-twogenerations

An, Z., McLaughlin, M., Hou, J., Nam, Y., Hu, C. W., Park, M., \& Meng, J. (2014). Social network representation and dissemination of pre-exposure prophylaxis (PrEP): A semantic network analysis of HIV prevention drug on twitter. Lecture Notes in Computer Science, 8531, 160-169. https://doi.org/10.1007/978-3-31907632-4_15

Andersen, S. M., Tuskeviciute, R., \& Przybylinski, E. (2017). Coherent variability: the self with significant others in memory and context. Social Cognition, 35(2), 107126. https://doi.org/10.1521/soco.2017.35.2.107

Anderson, P. L., Glidden, D. V., Liu, A., Buchbinder, S., Lama, J. R., Guanira, J. V., ... Grant, R. M. (2012). Emtricitabine-tenofovir exposure and pre-exposure prophylaxis efficacy in men who have sex with men. Science Translational Medicine, 4(151), 151ra125-151ra125. https://doi.org/10.1126/scitranslmed.3004006

Auerbach, J. D., \& Hoppe, T. A. (2015). Beyond "getting drugs into bodies": social science perspectives on pre-exposure prophylaxis for HIV. Journal of the International AIDS Society, 18(Suppl 3), 19983-19983.

https://doi.org/10.7448/IAS.18.4.19983 
RUNNING HEAD: Social judgments of sexual behavior and PrEP

Auerbach, J. D., Kinsky, S., Brown, G., \& Charles, V. (2015). Knowledge, attitudes, and likelihood of pre-exposure prophylaxis (PrEP) use among US women at risk of acquiring HIV. AIDS Patient Care and STDs, 29(2), 102-110. https://doi.org/10.1089/apc.2014.0142

Ayala, G., Makofane, K., Santos, G.-M., Beck, J., Do, T. D., Hebert, P., ... Arreola, S. (2013). Access to basic HIV-related services and PrEP acceptability among men who have sex with men worldwide: Barriers, facilitators, and implications for combination prevention. Journal of Sexually Transmitted Diseases, 2013(December 2011), 1-11. https://doi.org/10.1155/2013/953123

Baayen, R. H., Davidson, D. J., \& Bates, D. M. (2008). Mixed-effects modeling with crossed random effects for subjects and items. Journal of Memory and Language, 59(4), 390-412. https://doi.org/10.1016/j.jml.2007.12.005

Baker, B. (2015). “Truvada Whore”: taking the sting out of stigma. Retrieved from http://www.phillyvoice.com/arms-against-truvada-whore-stigma/

Barr, D. J. (2013). Random effects structure for testing interactions in linear mixedeffects models. Frontiers in Psychology, 4, 328-328. https://doi.org/10.3389/fpsyg.2013.00328

Barr, D. J., Levy, R., Scheepers, C., \& Tily, H. J. (2013). Random effects structure for confirmatory hypothesis testing: Keep it maximal. Journal of Memory and Language, 68(3), 255-278. https://doi.org/10.1016/j.jml.2012.11.001

Blackwell, C. W., Birnholtz, J., \& Abbott, C. (2014). Seeing and being seen: Co-situation and impression formation using Grindr, a location-aware gay dating app. New 
RUNNING HEAD: Social judgments of sexual behavior and PrEP

Media \& Society, 1461444814521595-.

https://doi.org/10.1177/1461444814521595

Brontsema, R. (2004). A queer revolution: Reconceptualizing the debate over linguistic reclamation. Colorado Research in Linguistics, 17(1), 1-17.

Brown, J., \& Trevethan, R. (2010). Shame, internalized homophobia, identity formation, attachment style, and the connection to relationship status in gay men. American Journal of Men's Health, 4(3), 267-276.

https://doi.org/10.1177/1557988309342002

Calabrese, S. K., \& Underhill, K. (2015). How stigma surrounding the use of HIV preexposure prophylaxis undermines prevention and pleasure: A call to destigmatize “Truvada Whores." American Journal of Public Health, 105(10), 1960-1964. https://doi.org/10.2105/AJPH.2015.302816

Calabrese, S. K., Underhill, K., Earnshaw, V. A., Hansen, N. B., Kershaw, T. S., Magnus, M., ... Dovidio, J. F. (2016). Framing HIV Pre-Exposure Prophylaxis (PrEP) for the General Public: How Inclusive Messaging May Prevent Prejudice from Diminishing Public Support. AIDS and Behavior, 20(7), 1499-1513. https://doi.org/10.1007/s10461-016-1318-9

Coelho, T. (2011). Hearts, groins and the intricacies of gay male open relationships: Sexual desire and liberation revisited. Sexualities, 14(6), 653-668. https://doi.org/10.1177/1363460711422306

Crary, D. (2014). Divide over HIV prevention drug Truvada persists. Retrieved from Out Smart website: http://www.outsmartmagazine.com/2014/04/gay-men-divided-usehiv-prevention-drug/ 
RUNNING HEAD: Social judgments of sexual behavior and PrEP

Crawford, M. T., Sherman, S. J., \& Hamilton, D. L. (2002). Perceived entitativity, stereotype formation, and the interchangeability of group members. Journal of Personality and Social Psychology, 83(5), 1076-1094. https://doi.org/10.1037/0022-3514.83.5.1076

Cuddy, A. J. C., Fiske, S. T., \& Glick, P. (2008). Warmth and competence as universal dimensions of social perception: the stereotype content model and the BIAS map. In M. Zanna (Ed.), Advances in Experimental Social Psychology (1st ed., Vol. 40, pp. 61-149). https://doi.org/10.1016/S0065-2601(07)00002-0

Davis, M., Hart, G., Bolding, G., Sherr, L., \& Elford, J. (2013). Sex and the internet: gay men, risk reduction and serostatus. Culture, Health \& Sexuality, 8(2), 161-174. https://doi.org/10.1080/13691050500526126

De Houwer, J., Thomas, S., \& Baeyens, F. (2001). Associative learning of likes and dislikes: a review of 25 years of research on human evaluative conditioning. Psychological Bulletin, 127(6), 853-869. https://doi.org/10.1037/00332909.127.6.853

Donnell, D., Baeten, J. M., Bumpus, N. N., Brantley, J., Bangsberg, D. R., Haberer, J. E., ... Celum, C. (2014). HIV protective efficacy and correlates of tenofovir blood concentrations in a clinical trial of PrEP for HIV prevention. Journal of Acquired Immune Deficiency Syndromes, 66(3), Epublished 2014 Apr 29-Epublished 2014 Apr 29. https://doi.org/10.1097/QAI.0000000000000172

Duran, D. (2012). Truvada Whores? Retrieved from http://www.huffingtonpost.com/david-duran/truvada-whores_b_2113588.html 
RUNNING HEAD: Social judgments of sexual behavior and PrEP

Eckes, T. (2002). Paternalistic and envious gender stereotypes: Testing predictions from the stereotype content model. Sex Roles, 16.

Elford, J., Bolding, G., \& Sherr, L. (2001). Seeking sex on the internet and sexual risk behaviour among gay men using London gyms. AIDS, 15(11), 1409-1415. https://doi.org/10.1097/00002030-200107270-00010

Engel, G. L. (1980). The clinical application of the biopsychosocial model. The American Journal of Psychiatry, 137(5), 535-544. https://doi.org/10.1176/ajp.137.5.535

Fiske, S. T., Cuddy, A. J. C., \& Glick, P. (2007). Universal dimensions of social cognition: warmth and competence. Trends in Cognitive Sciences, 11(2), 77-83. https://doi.org/10.1016/j.tics.2006.11.005

Gallagher, T., Link, L., Ramos, M., Bottger, E., Adberg, J., \& Daskalakis, D. (2014). Self-perception of HIV risk and candidacy for pre-exposure prophylaxis among men Who have sex with men testing for HIV at commercial sex venues in New York City. LGBT Health, 1(3), 1-7. https://doi.org/10.1089/1gbt.2013.0046

Gawronski, B., \& Bodenhausen, G. V. (2011). The Associative - Propositional Evaluation Model: Theory, Evidence, and Open Questions. In J. M. Olson \& M. P. Zanna (Eds.), Advances in Experimental Social Psychology (1st ed., Vol. 44, pp. 59-127). https://doi.org/10.1016/B978-0-12-385522-0.00002-0

Gawronski, B., \& Cesario, J. (2013). Of mice and men: what animal research can tell us about context effects on automatic responses in humans. Personality and Social Psychology Review, 17(2), 187-215. https://doi.org/10.1177/1088868313480096 
RUNNING HEAD: Social judgments of sexual behavior and PrEP

Gawronski, B., Geschke, D., \& Banse, R. (2003). Implicit bias in impression formation: Associations influence the construal of individuating information. European Journal of Social Psychology, 33(5), 573-589. https://doi.org/10.1002/ejsp.166

Gawronski, B., \& Quinn, K. A. (2013). Guilty by mere similarity: Assimilative effects of facial resemblance on automatic evaluation. Journal of Experimental Social Psychology, 49(1), 120-125. https://doi.org/10.1016/j.jesp.2012.07.016

Gillespie, B. J., Frederick, D., Harari, L., \& Grov, C. (2015). Homophily, close friendship, and life satisfaction among gay, lesbian, heterosexual, and bisexual men and women. PloS One, 10(6), e0128900-e0128900. https://doi.org/10.1371/journal.pone.0128900

Glaser, T., Dickel, N., Liersch, B., Rees, J., Süssenbach, P., \& Bohner, G. (2015). Lateral attitude change. Personality and Social Psychology Review, 19(3), 257-276. https://doi.org/10.1177/1088868314546489

Glazek, C. (2016). Why I am a Truvada Whore. Retrieved from http://www.out.com/entertainment/popnography/2014/05/20/why-i-am-truvadawhore

Grant, D., \& Marshall, K. (2013). Next steps for PrEP: Getting a proven prevention option to the people who need it. GMHC Treatment Issues, 1-4.

Grant, R. M., Anderson, P. L., McMahan, V., Liu, A., Amico, K. R., Mehrotra, M., ... Glidden, D. V. (2014). Uptake of pre-exposure prophylaxis, sexual practices, and HIV incidence in men and transgender women who have sex with men: a cohort study. The Lancet Infectious Diseases, 14(9), 820-829. https://doi.org/10.1016/S1473-3099(14)70847-3 
RUNNING HEAD: Social judgments of sexual behavior and PrEP

Green, P., \& Macleod, C. J. (2016). SIMR: An R package for power analysis of generalized linear mixed models by simulation. Methods in Ecology and Evolution, 7(4), 493-498. https://doi.org/10.1111/2041-210X.12504

Grov, C., Whitfield, T. H. F., Rendina, H. J., Ventuneac, A., \& Parsons, J. T. (2015). Willingness to take PrEP and potential for risk compensation among highly sexually active gay and bisexual men. AIDS and Behavior, 19, 2234-2244. https://doi.org/10.1007/s10461-015-1030-1

Haire, B. G. (2015). Preexposure prophylaxis-related stigma : strategies to improve uptake and adherence - a narrative review. HIV/AIDS - Research and Palliative Care, 7, 241-249. https://doi.org/10.2147/HIV.S72419

Halkitis, P. N. (2010). Reframing HIV prevention for gay men in the United States. American Psychologist, 65(8), 752-763. https://doi.org/10.1037/0003066X.65.8.752

Halkitis, P. N., Wolitski, R. J., \& Millett, G. A. (2013). A holistic approach to addressing HIV infection disparities in gay, bisexual, and other men who have sex with men. American Psychologist, 68(4), 261-273. https://doi.org/10.1037/a0032746

Hebl, M. R., \& Mannix, L. M. (2003). The weight of obesity in evaluating others: a mere proximity effect. Personality and Social Psychology Bulletin, 29(1), 28-38. https://doi.org/10.1177/0146167202238369

Hoenig, J. M., \& Heisey, D. M. (2001). The Abuse of Power: The Pervasive Fallacy of Power Calculations for Data Analysis. The American Statistician, 55(1), 19-24. 
RUNNING HEAD: Social judgments of sexual behavior and PrEP

Hofmann, W., De Houwer, J., Perugini, M., Baeyens, F., \& Crombez, G. (2010).

Evaluative conditioning in humans: a meta-analysis. Psychological Bulletin, 136(3), 390-421. https://doi.org/10.1037/a0018916

Horvath, K. J., Rosser, B. R. S., \& Remafedi, G. (2008). Sexual risk taking among young internet-using men who have sex with men. American Journal of Public Health, 98(6), 1059-1067. https://doi.org/10.2105/AJPH.2007.111070

Jiang, J., Yang, X., Ye, L., Zhou, B., Ning, C., Huang, J., ... Liang, H. (2014). Preexposure prophylaxis for the prevention of HIV infection in high risk populations: A meta-analysis of randomized controlled trials. PLoS ONE, 9(2), e87674e87674. https://doi.org/10.1371/journal.pone.0087674

Judd, C. M., Westfall, J., \& Kenny, D. A. (2012). Treating stimuli as a random factor in social psychology: A new and comprehensive solution to a pervasive but largely ignored problem. Journal of Personality and Social Psychology, 103(1), 54-69. https://doi.org/10.1037/a0028347

Kirby, T., \& Thornber-Dunwell, M. (2014). Uptake of PrEP for HIV slow among MSM. The Lancet, 383(9915), 399-400. https://doi.org/10.1016/S0140-6736(14)60137-9

Krakower, D. S., Mimiaga, M. J., Rosenberger, J. G., Novak, D. S., Mitty, J. A., White, J. M., \& Mayer, K. H. (2012). Limited awareness and low immediate uptake of preexposure prophylaxis among men who have sex with men using an internet social networking site. PLoS ONE, 7(3). https://doi.org/10.1371/journal.pone.0033119

Lenth, R. V., \& Hervé, M. (2015). lsmeans: Least-Squares Means. Retrieved from http://cran.r-project.org/package=lsmeans 
RUNNING HEAD: Social judgments of sexual behavior and PrEP

Liu, A., Cohen, S., Follansbee, S., Cohan, D., Weber, S., Sachdev, D., \& Buchbinder, S. (2014). Early experiences implementing pre-exposure prophylaxis (PrEP) for HIV prevention in San Francisco. PLoS Medicine, 11(3), 1-6. https://doi.org/10.1371/journal.pmed.1001613

Martinez, J. E., \& Jonas, K. J. (2019). Pre-exposure prophylaxis sorting among men who have sex with men. AIDS Care, 31(3), 388-396. https://doi.org/10.1080/09540121.2018.1533229

Martinez, J. E., Mack, M. L., Gelman, B. D., \& Preston, A. R. (2016). Knowledge of social affiliations biases economic decisions. PLOS ONE, 11(7), e0159918e0159918. https://doi.org/10.1371/journal.pone.0159918

McDavitt, B., \& Mutchler, M. G. (2014). “Dude, you're such a slut!” Barriers and facilitators of sexual communication among young gay men and their best friends. Journal of Adolescent Research, 29(4), 464-498. https://doi.org/10.1177/0743558414528974

Mettey, A., Crosby, R., DiClemente, R. J., \& Holtgrave, D. R. (2003). Associations between internet sex seeking and STI associated risk behaviours among men who have sex with men. Sexually Transmitted Infections, 79(6), 466-468. https://doi.org/10.1136/sti.79.6.466

Ogilvie, G. S., Taylor, D. L., Trussler, T., Marchand, R., Gilbert, M., Moniruzzaman, A., \& Rekart, M. L. (2008). Seeking sexual partners on the internet: A marker for risky sexual behaviour in men who have sex with men. Canadian Journal of Public Health, 99(3), 185-188. 
RUNNING HEAD: Social judgments of sexual behavior and PrEP

Peng, B., Yang, X., Zhang, Y., Dai, J., Liang, H., Zou, Y., ... Huang, A. (2012). Willingness to use pre-exposure prophylaxis for HIV prevention among female sex workers: a cross-sectional study in China. HIV/AIDS - Research and Palliative Care, 4, 149-158. https://doi.org/10.2147/HIV.S33445

Pérez-Figueroa, R. E., Kapadia, F., Barton, S. C., Eddy, J. A., \& Halkitis, P. N. (2015). Acceptability of PrEP uptake among racially/ethnically diverse young men who have sex with men: The P18 study. AIDS Education and Prevention, 27(2), 112125.

Przybylinski, E., \& Andersen, S. M. (2012). Making interpersonal meaning: Significant others in mind in transference. Social and Personality Psychology Compass, 6(10), 746-759. https://doi.org/10.1111/j.1751-9004.2012.00460.x

Quirk, C. C., Wolitski, R. J., Parsons, J. T., Gómez, C. A., \& Men, U. (2006). Is HIV/AIDS stigma dividing the gay community? Perceptions of HIV-positive men who have sex with men. AIDS Education and Prevention, 18(1), 56-67. https://doi.org/10.1521/aeap.2006.18.1.56

Ranganath, K. A., \& Nosek, B. A. (2008). Implicit attitude generalization occurs immediately; explicit attitude generalization takes time. Psychological Science, 19(3), 249-254. https://doi.org/10.1111/j.1467-9280.2008.02076.x

Ratliff, K. A., \& Nosek, B. A. (2011). Negativity and outgroup biases in attitude formation and transfer. Personality and Social Psychology Bulletin, 37, 16921703. https://doi.org/10.1177/0146167211420168 
RUNNING HEAD: Social judgments of sexual behavior and PrEP

Reynolds, D. (2014). 35 activists, doctors, and organizations speak out in support of PrEP. Retrieved from http://www.advocate.com/31-days-prep/2014/10/24/35activists-doctors-and-organizations-speak-out-support-prep

Rosenberg, S., Nelson, C., Vivekananthan, P. S., \& Johnstone, T. (1968). A multidimensional approach to the structure of personality impressions. Journal of Personality and Social Psychology, 9(4), 283-294. https://doi.org/10.1037/h0026086

Rouder, J. N., Morey, R. D., Speckman, P. L., \& Province, J. M. (2012). Default Bayes factors for ANOVA designs. Journal of Mathematical Psychology, 56(5), 356374. https://doi.org/10.1016/j.jmp.2012.08.001

Schlichting, M. L., \& Preston, A. R. (2015). Memory integration: neural mechanisms and implications for behavior. Current Opinion in Behavioral Sciences, 1, 1-8. https://doi.org/10.1016/j.cobeha.2014.07.005

Smit, P. J., Brady, M., Carter, M., Fernandes, R., Lamore, L., Meulbroek, M., ... Thompson, M. (2011). HIV-related stigma within communities of gay men: a literature review. AIDS Care, 24(April), 1-8. https://doi.org/10.1080/09540121.2011.613910

Sobo, J. (2012). Does taking PrEP make me a whore? Retrieved from https://www.frontiersmedia.com/channel-my-life-on-prep/2012/11/29/doestaking-prep-make-me-a-whore/

Spieldenner, A. (2016). PrEP Whores and HIV Prevention: The Queer Communication of HIV Pre-Exposure Prophylaxis (PrEP). Journal of Homosexuality, 63(12), 16851697. https://doi.org/10.1080/00918369.2016.1158012 
RUNNING HEAD: Social judgments of sexual behavior and PrEP

Stark, T. H., Flache, A., \& Veenstra, R. (2013). Generalization of positive and negative attitudes toward individuals to outgroup attitudes. Personality \& Social Psychology Bulletin, 39(5), 608-622. https://doi.org/10.1177/0146167213480890

Suls, J., \& Rothman, A. (2004). Evolution of the biopsychosocial model: Prospects and challenges for health psychology. Health Psychology, 23(2), 119-125. https://doi.org/10.1037/0278-6133.23.2.119

Uleman, J. S., Adil Saribay, S., \& Gonzalez, C. M. (2008). Spontaneous inferences, implicit impressions, and implicit theories. Annual Review of Psychology, 59, 329-360. https://doi.org/10.1146/annurev.psych.59.103006.093707

Verosky, S. C., \& Todorov, A. (2013). When physical similarity matters: Mechanisms underlying affective learning generalization to the evaluation of novel faces. Journal of Experimental Social Psychology, 49(4), 661-669. https://doi.org/10.1016/j.jesp.2013.02.004

Walther, E. (2002). Guilty by mere association: Evaluative conditioning and the spreading attitude effect. Journal of Personality and Social Psychology, 82(6), 919-934. https://doi.org/10.1037//0022-3514.82.6.919

Weston, K. (1991). Families we choose: Lesbians, Gays, Kinship. New York, NY: Columbia University Press.

Wimmer, G. E., \& Shohamy, D. (2012). Preference by association: How memory mechanisms in the hippocampus bias decisions. Science, 338(6104), 270-273. https://doi.org/10.1126/science.1223252 
RUNNING HEAD: Social judgments of sexual behavior and PrEP

Wojciszke, B. (2005). Morality and competence in person- and self-perception. European Review of Social Psychology, 16(1), 155-188.

https://doi.org/10.1080/10463280500229619

Zeithamova, D., Dominick, A. L., \& Preston, A. R. (2012). Hippocampal and ventral medial prefrontal activation during retrieval-mediated learning supports novel inference. Neuron, 75(1), 168-179. https://doi.org/10.1016/j.neuron.2012.05.010 
RUNNING HEAD: Social judgments of sexual behavior and PrEP

\section{Supplementary}

Contents:

- $\quad$ Stimuli

○ Table A:

- Eight vignettes used for the study.

- $\quad$ Additional statistics for main analyses

○ Table B:

- Raw means and standard deviations of responsibility and

○ Table C: trustworthiness ratings per condition for Figure $1 \mathrm{~A}$ and $\mathrm{B}$.

- Regression results for both the responsible and trustworthy trait ratings of the main and friend characters.

- Exploratory group moderator analyses

- Text on the motivation, method, results, and discussion of these analyses.

○ Figure S1:

- Group differences in responsibility ratings for the main character.

○ Table D:

- Raw means and standard deviations of responsibility ratings per demographic group derived for Figure 2 A and B.

○ Table E:

- Regression results for the interest in PrEP and Truvada Whore discriminatory attitude moderator analyses of main character trait ratings.

○ Table F:

- Regression results for the HIV and PrEP status moderator analyses of main character trait ratings. 


\section{Stimuli}

Table A.

Eight vignettes used for the study.

\begin{tabular}{|c|c|c|c|c|}
\hline & Content & $\begin{array}{c}\text { PrEP } \\
\text { use }\end{array}$ & $\begin{array}{c}\text { Sex } \\
\text { Behavior }\end{array}$ & Activity \\
\hline 1 & $\begin{array}{l}\text { X takes Truvada and likes to go to circuit } \\
\text { parties and have tons of unprotected sex. He } \\
\text { tells his good friend B that he is safe enough } \\
\text { with the pill. X and B cook dinner for their } \\
\text { friends one a week. }\end{array}$ & PrEP & FCP & Food \\
\hline 2 & $\begin{array}{l}\mathrm{V} \text { and his good friend } \mathrm{D} \text { host a movie night } \\
\text { every weekend. V uses Truvada and loves to } \\
\text { sleep with as many bareback gays at the local } \\
\text { bath house. }\end{array}$ & PrEP & FCP & Leisure \\
\hline 3 & $\begin{array}{l}\mathrm{T} \text { and his boyfriend fuck raw and take Truvada } \\
\text { daily for safety. F, T's good friend, often goes } \\
\text { on road trips with him. }\end{array}$ & PrEP & Monogamous & Travel \\
\hline 4 & $\begin{array}{l}\text { R's boyfriend loves when } R \text { uses spit to slide } \\
\text { deep into him during sex. They take Truvada } \\
\text { to be safe. R's friend } H \text { has been trying to } \\
\text { convince him to join his running team for a } \\
\text { while. }\end{array}$ & PrEP & Monogamous & Fitness \\
\hline 5 & $\begin{array}{l}\text { G often has unprotected sex multiple times a } \\
\text { day and doesn't take Truvada. He and his good } \\
\text { friend } \mathrm{S} \text { go cycling together regularly. }\end{array}$ & NoPrEP & FCP & Fitness \\
\hline 6 & $\begin{array}{l}\text { E loves bareback sex, especially in orgies. He } \\
\text { doesn't take Truvada. His friend U often } \\
\text { travels on vacations with E. }\end{array}$ & NoPrEP & FCP & Travel \\
\hline 7 & $\begin{array}{l}\mathrm{C} \text { and } \mathrm{W} \text { are good buds who go often to } \\
\text { brunch on the weekends. C confided in W that } \\
\text { he and his boyfriend don't use condoms when } \\
\text { they fuck. C does not use Truvada. }\end{array}$ & NoPrEP & Monogamous & Food \\
\hline 8 & $\begin{array}{l}\text { A and his boyfriend have bareback sex often } \\
\text { and he doesn't take Truvada. Y, a mutual } \\
\text { friend, often walks his dog with A at the park. }\end{array}$ & NoPrEP & Monogamous & Leisure \\
\hline
\end{tabular}


RUNNING HEAD: Social judgments of sexual behavior and PrEP

\section{Additional statistics for main analyses}

Table B.

Raw means and standard deviations of responsibility and trustworthiness ratings per condition for Figure $1 A$ and $B$.

\begin{tabular}{|c|c|c|c|c|c|c|c|c|}
\hline \multirow[b]{3}{*}{ Rating } & \multicolumn{4}{|c|}{$\begin{array}{l}\text { Main Character } \\
(\mathrm{n}=258)\end{array}$} & \multicolumn{4}{|c|}{$\begin{array}{l}\text { Friend Character } \\
\qquad(\mathrm{n}=258)\end{array}$} \\
\hline & \multicolumn{2}{|c|}{ Monogamous } & \multicolumn{2}{|c|}{$\mathrm{FCP}$} & \multicolumn{2}{|c|}{ Monogamous } & \multicolumn{2}{|c|}{ FCP } \\
\hline & PrEP & NoPrEP & PrEP & NoPrEP & PrEP & NoPrEP & PrEP & NoPrEP \\
\hline \multirow[t]{2}{*}{ Responsibility } & 3.69 & 2.81 & 2.16 & 1.57 & 3.47 & 3.34 & 3.26 & 3.19 \\
\hline & $(.98)$ & $(.98)$ & $(1.02)$ & $(.83)$ & $(.74)$ & $(.76)$ & $(.73)$ & $(.73)$ \\
\hline \multirow[t]{2}{*}{ Trustworthiness } & 3.57 & 3.17 & 2.59 & 2.23 & 3.45 & 3.39 & 3.28 & 3.20 \\
\hline & $(.85)$ & $(.87)$ & $(1.05)$ & $(1.05)$ & $(.75)$ & $(.77)$ & $(.71)$ & $(.69)$ \\
\hline
\end{tabular}

Note: Mean $(S D)$. FCP $=$ frequently changing partners. 
RUNNING HEAD: Social judgments of sexual behavior and PrEP

Table C.

Regression results for both the responsible and trustworthy trait ratings of the main and friend characters.

\section{Responsible Trustworthy}

Predictor Comparison $\quad$ B $95 \%$ d $\quad$ p $\quad$ B $95 \%$ d $\quad p$

Charact

(SE) CI

(SE) CI

\begin{tabular}{|c|c|c|c|c|c|c|c|c|c|c|}
\hline Main & & & & & & & & & & \\
\hline & $\begin{array}{l}\text { Sexual } \\
\text { behavior } \\
\text { (SB) }\end{array}$ & & & & & & & & & \\
\hline & Within PrEP & $\begin{array}{r}F C P- \\
\text { Monogamous }\end{array}$ & $\begin{array}{l}-1.52 \\
(07)\end{array}$ & $\begin{array}{l}-1.7 \\
-14\end{array}$ & 2.3 & $<.0001$ & $\begin{array}{l}-.99 \\
(08)\end{array}$ & $\begin{array}{l}-1.2 \\
-83\end{array}$ & 1.6 & $<.0001$ \\
\hline & Within & $F C P$ & -1.24 & -1.4 & 1.9 & $<.0001$ & -.94 & -1.1 , & 1.5 & $<.0001$ \\
\hline & NoPrEP & Monogamous & & & & & & -.78 & & \\
\hline & $\begin{array}{l}\text { PrEP use } \\
\text { (PU) }\end{array}$ & & & & & & & & & \\
\hline & $\begin{array}{r}\text { Within } \\
\text { Monogamous }\end{array}$ & $\begin{array}{r}\text { NoPrEP - } \\
\operatorname{PrEP}\end{array}$ & $\begin{array}{l}-.88 \\
(.06)\end{array}$ & $\begin{array}{l}-1.0 \\
-.75\end{array}$ & 1.3 & $<.0001$ & $\begin{array}{l}-.40 \\
(.07)\end{array}$ & $\begin{array}{l}-.54 \\
-.26\end{array}$ & .64 & $<.0001$ \\
\hline & Within FCP & $\begin{array}{r}\text { NoPrEP - } \\
\operatorname{Pr} E P\end{array}$ & -.59 & -.71 & .90 & $<.0001$ & -.35 & -.49 , & .56 & $<.0001$ \\
\hline & SB $x$ PU & 1 & 28 & 15 & 43 & 0002 & 05 & -13 & 07 & 593 \\
\hline & Interaction & & $(.07)$ & .42 & & & $(.08)$ & .23 & & \\
\hline \multicolumn{11}{|l|}{ Friend } \\
\hline & $\begin{array}{l}\text { Sexual } \\
\text { behavior } \\
\text { (SB) }\end{array}$ & & & & & & & & & \\
\hline & Within PrEP & $F C P$ & -.21 & -.31 & .32 & .0001 & -.17 & -.29 , & .27 & .009 \\
\hline & & Monogamous & $(.05)$ & -.11 & & & $(.06)$ & -.05 & & \\
\hline & $\begin{array}{r}\text { Within } \\
\text { NoPrEP }\end{array}$ & $\begin{array}{r}F C P \text { - } \\
\text { Monogamous }\end{array}$ & $\begin{array}{l}-.15 \\
(.04)\end{array}$ & $\begin{array}{l}-.24 \\
-.06\end{array}$ & .23 & .0023 & $\begin{array}{l}-.20 \\
(.05)\end{array}$ & $\begin{array}{l}-.31 \\
-.08\end{array}$ & .31 & .003 \\
\hline & $\begin{array}{l}\text { PrEP use } \\
\text { (PU) }\end{array}$ & & & & & & & & & \\
\hline & Within & NoPrEP - & -.13 & -.22 & .19 & .009 & -.05 & -.17 & .08 & .358 \\
\hline & Monogamous & $\operatorname{PrEP}$ & $(.05)$ & -.03 & & & $(.06)$ & .07 & & \\
\hline & Within FCP & $\begin{array}{r}\text { NoPrEP - } \\
\text { PrEP }\end{array}$ & $\begin{array}{l}-.07 \\
(.04)\end{array}$ & $\begin{array}{c}-.16 \\
.02\end{array}$ & .10 & .138 & $\begin{array}{l}-.08 \\
(.05)\end{array}$ & $\begin{array}{c}-.20 \\
.04\end{array}$ & .13 & .163 \\
\hline & SB x PU & & .06 & -.07 & .09 & .360 & -.03 & -.19 & .04 & .731 \\
\hline & Interaction & & $(.07)$ & .20 & & & $(.08)$ & .14 & & \\
\hline \multicolumn{11}{|l|}{ Both } \\
\hline & SB x PU x & & .22 & .06 & .34 & .007 & .07 & -.09 , & .12 & .380 \\
\hline & $\begin{array}{l}\text { Character } \\
\text { Interaction }\end{array}$ & & $(.08)$ & .38 & & & $(.08)$ & .24 & & \\
\hline
\end{tabular}

Note: The character column delineates different regression models. 
RUNNING HEAD: Social judgments of sexual behavior and PrEP

\section{Exploratory group moderator analyses}

The following are exploratory analyses that attempted to probe how the following three PrEP-relevant demographic demarcations might play a role in guiding responsibility and trustworthiness ratings reported in the main manuscript: participants' attitude about the discriminatory nature of "Truvada Whore", participants' interest in taking PrEP, and participants' current HIV and PrEP status. For sexual health status the focus was on four groups: individuals with HIV infection, individuals without HIV infection currently taking or not taking PrEP, and individuals who do not know or do not disclose their HIV status. HIV negative individuals who do not take PrEP may be the most likely to express less positive views of PrEP as they have had no experience with PrEP. Conversely, they may be open to the idea of PrEP since they already employ some safe sex practices such as knowing their status. HIV negative individuals who take PrEP have direct experience with PrEP and a mitigated sexual risk. Finally, although PrEP is not directly targeted at individuals living with HIV, they could either welcome the risk reduction strategies of PrEP users or propagate sexual shaming in relation to the perceived number of different partners often associated with PrEP use. Individuals who do not know their status or do not disclose may have a tentative relationship with safe sex practices and are possibly among the riskiest group. These complex dynamics could shift how each group perceives others' sexual health behaviors.

First, the analyses examined the role of PrEP attitudes and interest held by the HIV negative participants not taking PrEP from the main manuscript analyses, then probed the role of all participants' sexual health status.

\section{Method}


RUNNING HEAD: Social judgments of sexual behavior and PrEP

\section{Measures}

For exploratory moderator analyses for HIV negative individuals not currently taking PrEP, the following variables were included: interest in PrEP, 194 were and 63 were not and one did not respond, and an attitude measure on whether the term "Truvada Whore" is discriminatory $(1=$ strongly disagree, $5=$ strongly agree $), 33 \%$ chose $5,40 \%$ chose $4,16 \%$ chose $3,4 \%$ chose 2 , and $7 \%$ chose 1 .

\section{Data analysis}

The same mixed regression approach as stated in the main manuscript was used for these analyses.

Exploratory models included group variables that have potential to affect the interaction of interest for both responsibility and trustworthiness. One model included a categorical moderator designating whether the participants from the main analysis $(\mathrm{n}=$ 258) were interested in using PrEP or not and an attitude covariate that represented their agreement with whether the use of the term "Truvada Whore" was discriminatory. A separate model added a group moderator that compared the ratings of participants with different HIV and PrEP stati. The sample in this model further included individuals who are living with HIV $(n=25)$, individuals who are HIV negative and taking PrEP $(n=31)$, and individuals who did not know or did not disclose their status $(n=25)$ which composes the full eligible sample.

\section{Discriminatory attitudes}

The first factor we investigate that could potentially moderate social judgments of PrEP use is the way participants feel about the discriminatory nature of the term "Truvada Whore". There was a marginal effect of discrimination attitude on the 
RUNNING HEAD: Social judgments of sexual behavior and PrEP

responsibility ratings such that the more that participants agreed that "Truvada Whore" was discriminatory the greater their responsibility ratings overall, $b=.06, d=.08, \mathrm{SE}=$ $.034,95 \% \mathrm{CI}[-.004, .129], \mathrm{t}(257)=1.82, \mathrm{p}=.07$. Discrimination attitude had a similar effect for trustworthiness ratings, $\mathrm{b}=.06, \mathrm{~d}=.08, \mathrm{SE}=.038,95 \% \mathrm{CI}[-.01, .13], \mathrm{t}(257)=$ $1.47, \mathrm{p}=.144$. Generally, participants' attitude towards the discriminatory nature of "Truvada Whore" had a minor impact on their judgments.

Interest in taking PrEP

Another factor that could affect social judgments is whether participants are interested in starting PrEP themselves, such that those interested might have more favorable views of PrEP users. The Sexual Behavior x PrEP use x Interest interaction pattern in the responsibility ratings was not significant, $\mathrm{b}=.03, \mathrm{~d}=.05, \mathrm{SE}=.181,95 \%$ $\mathrm{CI}[-.33, .39], \mathrm{t}(257)=.192, \mathrm{p}=.848$. However, interest in taking PrEP interacted with the main character's PrEP use, $\mathrm{b}=.34, \mathrm{~d}=.46, \mathrm{SE}=.157,95 \% \mathrm{CI}[.03, .65], \mathrm{t}(257)=2.17, \mathrm{p}$ $=.031$; Figure S1A, but not Sexual behavior, $\mathrm{b}=.15, \mathrm{~d}=.21, \mathrm{SE}=.172,95 \% \mathrm{CI}[-.18$, $.49], t(257)=.901, p=.369$. The interaction was driven by greater responsibility ratings for PrEP using characters by participants interested in taking PrEP than participants who expressed no interest, $\mathrm{b}=.54, \mathrm{~d}=.73, \mathrm{SE}=.137,95 \% \mathrm{CI}[.27, .81], \mathrm{t}(257)=3.94, \mathrm{p}=$ .0001 . This difference was not observed in the ratings for NoPrEP characters, $b=.19, d=$ $.27, \mathrm{SE}=.140,95 \% \mathrm{CI}[-.08, .47], \mathrm{t}(257)=1.41, \mathrm{p}=.160$.

Trustworthiness judgments did not exhibit any interactions with interest in PrEP (ts $<1.64$, ps $>.382$ ).

HIV and PrEP Status 
RUNNING HEAD: Social judgments of sexual behavior and PrEP

One final group distinction that could moderate social judgments is whether participants are already living with HIV, whether they are already using PrEP, or do not know or disclose their status. There were no interactions with group for trustworthiness judgments $(\mathrm{ps}>.36)$, only for responsibility judgments so we focus on those results.

Within these additional groups, only those who did not disclose or know their status exhibited a marginal Sexual Behavior $x$ PrEP use interaction, $b=.44, d=.58, \mathrm{SE}=$ $.25,95 \%$ CI $[-.04, .93], \mathrm{t}(339)=1.78, \mathrm{p}=.076$. HIV negative individuals taking PrEP, $\mathrm{b}$ $=.31, \mathrm{~d}=.41, \mathrm{SE}=.22,95 \% \mathrm{CI}[.74, .13], \mathrm{t}(339)=1.38, \mathrm{p}=.168$, and individuals living with HIV did not, $\mathrm{b}=.28, \mathrm{~d}=.38, \mathrm{SE}=.25,95 \% \mathrm{CI}[-.21, .77], \mathrm{t}(339)=1.13, \mathrm{p}=.258$ Comparing the groups, the Sexual Behavior x PrEP use interaction was significantly different between HIV negative individuals using and not using $\operatorname{PrEP}, \mathrm{b}=.59, \mathrm{SE}=.237$, $95 \% \mathrm{CI}[.13,1.05], \mathrm{t}(339)=2.49, \mathrm{p}=.013$. All other group comparisons were not significant (ps > .54); Figure S1B. These interactions suggest that the pattern where monogamous characters gain an evaluative boost when using PrEP relative to FCP characters is not seen in participants living with HIV or who take PrEP.

Condition comparisons showed that most of the group differences occurred in evaluations of the FCP PrEP characters; Figure S1B. HIV negative participants that use PrEP rated the FCP PrEP characters as more responsible than HIV negative participants not currently using PrEP, $\mathrm{b}=.55, \mathrm{~d}=.73, \mathrm{SE}=.197,95 \% \mathrm{CI}[.16, .94], \mathrm{t}(339)=2.77, \mathrm{p}=$ .006. The same occurred descriptively where participants living with HIV also rated FCP PrEP characters as more responsible than HIV negative participants not using PrEP, $b=$ $.42, \mathrm{~d}=.56, \mathrm{SE}=.218,95 \% \mathrm{CI}[.01, .85], \mathrm{t}(339)=1.92, \mathrm{p}=.056$. Likewise, participants who do not know their status rated FCP PrEP characters as less responsible than HIV 
RUNNING HEAD: Social judgments of sexual behavior and PrEP

negative individuals who take PrEP, $\mathrm{b}=.67, \mathrm{~d}=.89, \mathrm{SE}=.28,95 \% \mathrm{CI}[.12,1.22], \mathrm{t}(339)$

$=2.40, \mathrm{p}=.017$, and individuals living with $\mathrm{HIV}, \mathrm{b}=.54, \mathrm{~d}=.72, \mathrm{SE}=.29,95 \% \mathrm{CI}[-$ $.03,1.12], \mathrm{t}(339)=1.84, \mathrm{p}=.066$. All other comparisons were non-significant $(\mathrm{ps}>$ $.111)$.

\section{Discussion}

Arguments against PrEP are characterized by the idea that PrEP leads to increased risky sex with many partners, which is generally considered immoral. Therefore, the "Truvada Whore" hypothesis predicted lower trustworthy and responsible evaluations for FCP and PrEP using characters. Instead only FCP led to negative evaluations, while PrEP use and monogamy were linked to positive evaluations. However, demographic variables shifted this pattern in ways that can identify some forms of relative PrEP stigmatization (Supplementary Figure S1). When taking the participant's interest in PrEP into account, less positive evaluations occurred mostly in men who have no interest in using PrEP. They rated characters who use PrEP as less responsible than participants interested in PrEP. Moreover, when taking current HIV and PrEP status into account, HIV negative participants who are not taking PrEP and those who do not disclose or know their status judged FCP PrEP using characters specifically as less responsible than participants living with HIV or HIV negative and currently taking PrEP. The evaluative pattern of individuals with no experience and no intentions of using PrEP showed evidence of relatively worse judgments of PrEP users, which is noteworthy as they are among the most vulnerable group to HIV infections in this sample. Conversely, the individuals living with HIV and PrEP taking individuals showed more positive evaluations for FCP PrEP users for reasons that might differ per group. However, given the open sampling 
RUNNING HEAD: Social judgments of sexual behavior and PrEP

technique, there was a small sample living with HIV, sample of individuals who do not know or disclose their status, and a sample of active PrEP users, and thus comparisons with these groups should be considered as tentative. Future studies, based on our findings should aim to gather a power-analysis defined sample, which was not possible in our case, given the novelty of the phenomenon.

Still, these group dynamics highlight two implications. First, it may well be the case that the evaluative patterns we captured are also tracking which character profiles are perceived to carry larger sexual health risks, although future research needs to directly measure this possibility. Second, the relatively positive evaluations of FCP PrEP characters by participants using PrEP or living with HIV suggest a need to explore how these two groups may play supporting roles in social interventions for PrEP uptake. 
RUNNING HEAD: Social judgments of sexual behavior and PrEP
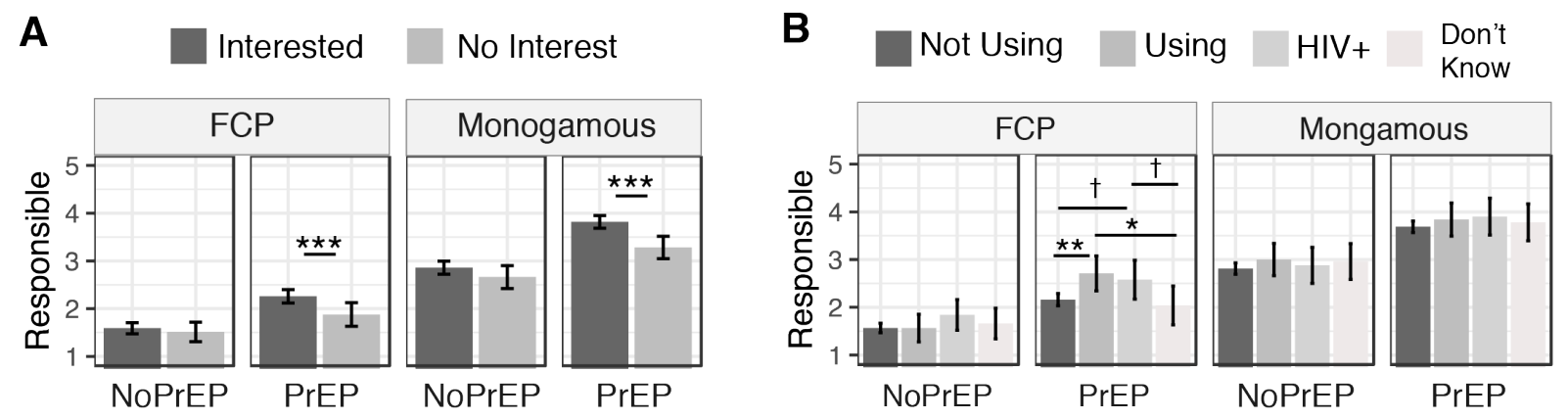

\section{Figure S1: Group differences in responsibility ratings for the main character.}

A) Ratings for the main characters grouped by participants who expressed interest in taking PrEP (dark grey) and those who expressed no interest (grey). B) Ratings for the main characters grouped by HIV negative participants who declared that they were currently using PrEP (medium dark grey) or not (darkest grey), individuals living with HIV (medium light grey), and those who did not know or disclose their status (lightest grey). Error bars represent 95\% confidence intervals. ${ }^{* *} \mathrm{p}<.01, * * * \mathrm{p}=.0001, \uparrow \mathrm{p}<.07 . \mathrm{FCP}=$ frequently changing partners. 
RUNNING HEAD: Social judgments of sexual behavior and PrEP

Table D.

Raw means and standard deviations of responsibility ratings per demographic group derived for Figure $2 A$ and $B$.

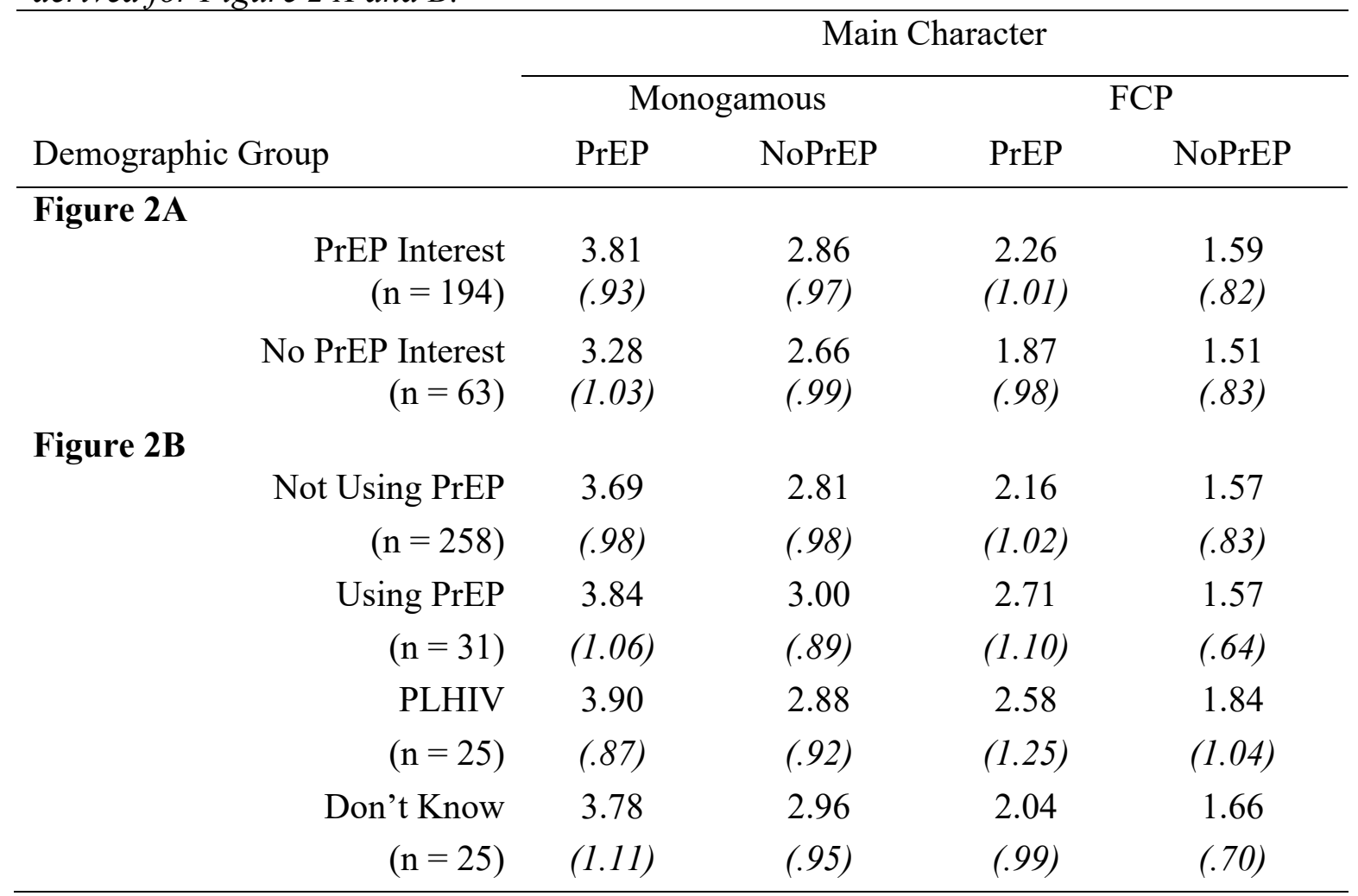

Note: Mean $(S D)$. FCP = frequently changing partners. 
RUNNING HEAD: Social judgments of sexual behavior and PrEP

Table E.

Regression results for the interest in PrEP and Truvada Whore discriminatory attitude moderators analyses of main character trait ratings.

\begin{tabular}{|c|c|c|c|c|c|c|c|c|c|}
\hline \multirow[b]{2}{*}{ Predictor } & \multirow[b]{2}{*}{ Comparison } & \multicolumn{4}{|c|}{ Responsible } & \multicolumn{4}{|c|}{ Trustworthy } \\
\hline & & $\begin{array}{c}\mathrm{B} \\
(\mathrm{SE})\end{array}$ & $\begin{array}{c}95 \% \\
\text { CI }\end{array}$ & $\mathrm{d}$ & $\mathrm{p}$ & $\begin{array}{c}\mathrm{B} \\
(\mathrm{SE})\end{array}$ & $\begin{array}{c}95 \% \\
\text { CI }\end{array}$ & d & $\mathrm{p}$ \\
\hline \multicolumn{10}{|l|}{ Attitude } \\
\hline Within NoPrEP, FCP & & $\begin{array}{l}.06 \\
(.03)\end{array}$ & $\begin{array}{c}-.004 \\
.13\end{array}$ & .08 & .070 & $\begin{array}{l}.06 \\
(.04)\end{array}$ & $\begin{array}{l}-.02 \\
.13\end{array}$ & .08 & .144 \\
\hline \multicolumn{10}{|l|}{ Interest in PrEP (IP) } \\
\hline $\begin{array}{l}\text { Within PrEP, } \\
\text { Monogamous }\end{array}$ & Yes - No & $\begin{array}{l}.54 \\
(.14)\end{array}$ & $.27, .80$ & .73 & .0001 & $\begin{array}{l}.27 \\
(.12)\end{array}$ & $.03, .51$ & .37 & .027 \\
\hline Within PrEP, FCP & Yes - No & $\begin{array}{l}.38 \\
(.14)\end{array}$ & $.10, .67$ & .52 & .009 & $\begin{array}{l}.21 \\
(.15)\end{array}$ & $\begin{array}{c}-.10 \\
.51\end{array}$ & .28 & .172 \\
\hline $\begin{array}{r}\text { Within NoPrEP, } \\
\text { Monogamous }\end{array}$ & $Y e s-N o$ & $\begin{array}{l}.19 \\
(.14)\end{array}$ & $\begin{array}{c}-.08, \\
.47\end{array}$ & .27 & .160 & $\begin{array}{l}.16 \\
(.12)\end{array}$ & $\begin{array}{c}-.09 \\
.41\end{array}$ & .22 & .201 \\
\hline Within NoPrEP, FCP & $Y e s-N o$ & $\begin{array}{l}.08 \\
(.12)\end{array}$ & $\begin{array}{c}-.16 \\
.31\end{array}$ & .11 & .515 & $\begin{array}{l}.01 \\
(.15)\end{array}$ & $\begin{array}{c}-.29 \\
.31\end{array}$ & .02 & .929 \\
\hline \multicolumn{10}{|l|}{ IP x SB Interaction } \\
\hline Within PrEP & & $\begin{array}{l}-.15 \\
(.17)\end{array}$ & $\begin{array}{c}-.49 \\
.18\end{array}$ & .21 & .368 & $\begin{array}{l}-.06 \\
(.16)\end{array}$ & $\begin{array}{c}-.39 \\
.26\end{array}$ & .09 & .699 \\
\hline Within NoPrEP & & $\begin{array}{l}-.12 \\
(.16)\end{array}$ & $\begin{array}{l}-.43 \\
.19\end{array}$ & .16 & .453 & $\begin{array}{l}.15 \\
(.16)\end{array}$ & $\begin{array}{l}-.47 \\
.17\end{array}$ & .20 & .370 \\
\hline \multicolumn{10}{|l|}{ IP x PU Interaction } \\
\hline Within Monogamous & & $\begin{array}{l}-.34 \\
(.16)\end{array}$ & $\begin{array}{l}-.65,- \\
.03\end{array}$ & .46 & .031 & $\begin{array}{l}-.22 \\
(.13)\end{array}$ & $\begin{array}{l}-.36 \\
.14\end{array}$ & .15 & .382 \\
\hline Within FCP & & $\begin{array}{l}-.31 \\
(.14)\end{array}$ & $\begin{array}{c}-.58,- \\
.03\end{array}$ & .41 & .032 & $\begin{array}{l}-.19 \\
(.12)\end{array}$ & $\begin{array}{c}-.42 \\
.04\end{array}$ & .26 & .101 \\
\hline \multicolumn{10}{|l|}{ SB x PU Interaction } \\
\hline Within Yes & & $\begin{array}{l}.29 \\
(.09)\end{array}$ & $.11, .47$ & .39 & .001 & $\begin{array}{l}.03 \\
(.09)\end{array}$ & $\begin{array}{l}-.16 \\
.22\end{array}$ & .04 & .752 \\
\hline Within No & & $\begin{array}{l}.25 \\
(.16)\end{array}$ & $\begin{array}{c}-.06 \\
.56\end{array}$ & .34 & .107 & $\begin{array}{l}.11 \\
(.14)\end{array}$ & $\begin{array}{c}-.17 \\
.40\end{array}$ & .15 & .439 \\
\hline $\begin{array}{l}\text { SB x PU x IP } \\
\text { Interaction }\end{array}$ & & $\begin{array}{l}-.03 \\
(.18)\end{array}$ & $\begin{array}{c}-.39 \\
.32\end{array}$ & .05 & .848 & $\begin{array}{l}.08 \\
(.16)\end{array}$ & $\begin{array}{l}-.23 \\
.40\end{array}$ & .11 & .600 \\
\hline
\end{tabular}

Note: The simple effects of sexual behavior and PrEP use not shown in this model to focus the table on the moderators, but they can be seen in the data archive. 
RUNNING HEAD: Social judgments of sexual behavior and PrEP

Table F.

Regression results for the HIV and PrEP status moderator analyses of main character trait ratings.

\begin{tabular}{|c|c|c|c|c|c|c|c|c|c|}
\hline \multirow[b]{2}{*}{ Predictor } & \multirow[b]{2}{*}{ Comparison } & \multicolumn{4}{|c|}{ Responsible } & \multicolumn{4}{|c|}{ Trustworthy } \\
\hline & & $\begin{array}{c}\mathrm{B} \\
(\mathrm{SE})\end{array}$ & $\begin{array}{c}95 \% \\
\text { CI }\end{array}$ & $\mathrm{d}$ & $\mathrm{p}$ & $\begin{array}{c}\mathrm{B} \\
(\mathrm{SE})\end{array}$ & $\begin{array}{c}95 \% \\
\mathrm{CI}\end{array}$ & $\mathrm{d}$ & $\mathrm{p}$ \\
\hline \multicolumn{10}{|l|}{$\begin{array}{l}\text { HIV/PrEP Status } \\
\text { (HPS) }\end{array}$} \\
\hline $\begin{array}{l}\text { Within PrEP, } \\
\text { Monogamous }\end{array}$ & $\begin{array}{r}\text { NegNT- } \\
\quad \text { NegYT }\end{array}$ & $\begin{array}{l}-.15 \\
(.19)\end{array}$ & $\begin{array}{c}-.52 \\
.22\end{array}$ & .20 & .419 & $\begin{array}{l}-.10 \\
(.16)\end{array}$ & $\begin{array}{c}-.43 \\
.22\end{array}$ & .14 & .529 \\
\hline $\begin{array}{l}\text { Within PrEP, } \\
\text { Monogamous }\end{array}$ & NegNT-PLHIV & $\begin{array}{l}-.21 \\
(.21)\end{array}$ & $\begin{array}{l}-.62 \\
.19\end{array}$ & .28 & .303 & $\begin{array}{l}-.31 \\
(.18)\end{array}$ & $\begin{array}{l}-.66, \\
.05\end{array}$ & .42 & .092 \\
\hline $\begin{array}{l}\text { Within PrEP, } \\
\text { Monogamous }\end{array}$ & $N e g N T-D N D$ & $\begin{array}{l}-.09 \\
(.21)\end{array}$ & $\begin{array}{c}-.49 \\
.31\end{array}$ & .122 & .655 & $\begin{array}{l}-.07 \\
(.18)\end{array}$ & $\begin{array}{c}-.42 \\
.29\end{array}$ & .09 & .715 \\
\hline $\begin{array}{l}\text { Within PrEP, } \\
\text { Monogamous }\end{array}$ & $\begin{array}{r}\text { NegYT- } \\
\text { PLHIV }\end{array}$ & $\begin{array}{l}-.06 \\
(.26)\end{array}$ & $\begin{array}{c}-.58 \\
.46\end{array}$ & .08 & .816 & $\begin{array}{l}-.20 \\
(.23)\end{array}$ & $\begin{array}{c}-.66 \\
.26\end{array}$ & .28 & .385 \\
\hline $\begin{array}{l}\text { Within PrEP, } \\
\text { Monogamous }\end{array}$ & $N e g Y T-D N D$ & $\begin{array}{l}.06 \\
(.26)\end{array}$ & $\begin{array}{c}-.46 \\
.58\end{array}$ & .08 & .824 & $\begin{array}{l}-04 \\
(.23)\end{array}$ & $\begin{array}{c}-.42 \\
.49\end{array}$ & .05 & .872 \\
\hline $\begin{array}{l}\text { Within PrEP, } \\
\text { Monogamous }\end{array}$ & $P L H I V$ - DND & $\begin{array}{l}.12 \\
(.28)\end{array}$ & $\begin{array}{c}-.43 \\
.67\end{array}$ & .16 & .666 & $\begin{array}{l}.24 \\
(.25)\end{array}$ & $\begin{array}{l}-.24 \\
.72\end{array}$ & .33 & .328 \\
\hline $\begin{array}{r}\text { Within NoPrEP, } \\
\text { Monogamous }\end{array}$ & $\begin{array}{r}\text { NegNT- } \\
\text { NegYT }\end{array}$ & $\begin{array}{l}-.19 \\
(.18)\end{array}$ & $\begin{array}{l}-.54 \\
.17\end{array}$ & .25 & .302 & $\begin{array}{l}-.01 \\
(.17)\end{array}$ & $\begin{array}{l}-.33 \\
.32\end{array}$ & .01 & .967 \\
\hline $\begin{array}{r}\text { Within NoPrEP, } \\
\text { Monogamous }\end{array}$ & NegNT-PLHIV & $\begin{array}{l}-.07 \\
(.20)\end{array}$ & $\begin{array}{c}-.46 \\
.33\end{array}$ & .09 & .734 & $\begin{array}{l}-.03 \\
(.18)\end{array}$ & $\begin{array}{c}-.39 \\
.32\end{array}$ & .04 & .871 \\
\hline $\begin{array}{r}\text { Within NoPrEP, } \\
\text { Monogamous }\end{array}$ & NegNT - DND & $\begin{array}{l}-.15 \\
(.20)\end{array}$ & $\begin{array}{l}-.54 \\
.25\end{array}$ & .20 & .460 & $\begin{array}{l}.13 \\
(.18)\end{array}$ & $\begin{array}{c}-.23 \\
.49\end{array}$ & .18 & .474 \\
\hline $\begin{array}{r}\text { Within NoPrEP, } \\
\text { Monogamous }\end{array}$ & $\begin{array}{r}\text { NegYT- } \\
\text { PLHIV }\end{array}$ & $\begin{array}{l}.12 \\
(.26)\end{array}$ & $\begin{array}{l}-.39 \\
.63\end{array}$ & .16 & .641 & $\begin{array}{l}-.02 \\
(.23)\end{array}$ & $\begin{array}{c}-.48 \\
.44\end{array}$ & .03 & .923 \\
\hline $\begin{array}{r}\text { Within NoPrEP, } \\
\text { Monogamous }\end{array}$ & $N e g Y T-D N D$ & $\begin{array}{l}.04 \\
(.26)\end{array}$ & $\begin{array}{c}-.47 \\
.55\end{array}$ & .05 & .876 & $\begin{array}{l}.14 \\
(.23)\end{array}$ & $\begin{array}{l}-.32 \\
.59\end{array}$ & .19 & .557 \\
\hline $\begin{array}{r}\text { Within NoPrEP, } \\
\text { Monogamous }\end{array}$ & $P L H I V-D N D$ & $\begin{array}{l}-.08 \\
(.27)\end{array}$ & $\begin{array}{l}-.61 \\
.45\end{array}$ & .11 & .767 & $\begin{array}{l}.16 \\
(.25)\end{array}$ & $\begin{array}{l}-.32 \\
.64\end{array}$ & .22 & .515 \\
\hline Within PrEP, FCP & $\begin{array}{r}\text { NegNT- } \\
\text { NegYT }\end{array}$ & $\begin{array}{l}-.55 \\
(.20)\end{array}$ & $\begin{array}{c}-.94,- \\
.16\end{array}$ & .73 & .006 & $\begin{array}{l}-.24 \\
(.20)\end{array}$ & $\begin{array}{l}-.63 \\
.16\end{array}$ & .32 & .241 \\
\hline Within PrEP, FCP & NegNT-PLHIV & $\begin{array}{l}-.42 \\
(.22)\end{array}$ & $\begin{array}{l}-.85 \\
.008\end{array}$ & .56 & .054 & $\begin{array}{l}-.37 \\
(.22)\end{array}$ & $\begin{array}{c}-.81 \\
.06\end{array}$ & .51 & .092 \\
\hline Within PrEP, FCP & $N e g N T-D N D$ & $\begin{array}{l}.12 \\
(.22)\end{array}$ & $\begin{array}{l}-.31 \\
.55\end{array}$ & .16 & .578 & $\begin{array}{l}.19 \\
(.22)\end{array}$ & $\begin{array}{c}-.25 \\
.62\end{array}$ & .26 & .397 \\
\hline Within PrEP, FCP & $\begin{array}{r}\text { NegYT- } \\
\text { PLHIV }\end{array}$ & $\begin{array}{l}.13 \\
(.28)\end{array}$ & $\begin{array}{c}-.42 \\
.68\end{array}$ & .17 & .642 & $\begin{array}{l}-.14 \\
(.28)\end{array}$ & $\begin{array}{c}-.69 \\
.42\end{array}$ & .19 & .628 \\
\hline Within PrEP, FCP & $N e g Y T-D N D$ & $\begin{array}{l}.67 \\
(.28)\end{array}$ & $.12,1.2$ & .89 & .017 & $\begin{array}{l}.42 \\
(.28)\end{array}$ & $\begin{array}{c}-.13 \\
.98\end{array}$ & .58 & .134 \\
\hline Within PrEP, FCP & $P L H I V$ - DND & $\begin{array}{l}.54 \\
(.29)\end{array}$ & $\begin{array}{c}-.04, \\
1.1\end{array}$ & .72 & .066 & $\begin{array}{l}.56 \\
(.30)\end{array}$ & $\begin{array}{l}-.03, \\
.1 .1\end{array}$ & .76 & .061 \\
\hline Within NoPrEP, FCP & $\begin{array}{r}\text { NegNT- } \\
\text { NegYT }\end{array}$ & $\begin{array}{l}.003 \\
(.15)\end{array}$ & $\begin{array}{l}-.30 \\
.31\end{array}$ & .004 & .983 & $\begin{array}{l}-.06 \\
(.19)\end{array}$ & $\begin{array}{c}-.43 \\
.31\end{array}$ & .08 & .752 \\
\hline Within NoPrEP, FCP & NegNT-PLHIV & $\begin{array}{l}-.27 \\
(.17)\end{array}$ & $\begin{array}{c}-.61 \\
.06\end{array}$ & .36 & .111 & $\begin{array}{l}-.07 \\
(.21)\end{array}$ & $\begin{array}{c}-.48 \\
.34\end{array}$ & .09 & .739 \\
\hline Within NoPrEP, FCP & $N e g N T-D N D$ & $\begin{array}{l}-.09 \\
(.17)\end{array}$ & $\begin{array}{c}-.43 \\
.24\end{array}$ & .12 & .589 & $\begin{array}{l}.17 \\
(.21)\end{array}$ & $\begin{array}{c}-.24 \\
.58\end{array}$ & .23 & .413 \\
\hline
\end{tabular}


RUNNING HEAD: Social judgments of sexual behavior and PrEP

\begin{tabular}{|c|c|c|c|c|c|c|c|c|c|}
\hline Within NoPrEP, FCP & $\begin{array}{r}\text { NegYT- } \\
\text { PLHIV }\end{array}$ & $\begin{array}{l}-.28 \\
(.22)\end{array}$ & $\begin{array}{l}-.71 \\
.15\end{array}$ & .37 & .208 & $\begin{array}{l}-.01 \\
(.27)\end{array}$ & $\begin{array}{l}-.54 \\
.52\end{array}$ & .01 & .971 \\
\hline Within NoPrEP, FCP & $N e g Y T-D N D$ & $\begin{array}{l}-.10 \\
(.22)\end{array}$ & $\begin{array}{l}-.53 \\
.33\end{array}$ & .13 & .663 & $\begin{array}{l}.23 \\
(.27)\end{array}$ & $\begin{array}{l}-.30 \\
.76\end{array}$ & .31 & .389 \\
\hline Within NoPrEP, FCP & $P L H I V$ - DND & $\begin{array}{l}.18 \\
(.23)\end{array}$ & $\begin{array}{l}-.27 \\
.63\end{array}$ & .24 & .434 & $\begin{array}{c}.24 \\
(.28)\end{array}$ & $\begin{array}{l}-.31 \\
.79\end{array}$ & .33 & .394 \\
\hline \multicolumn{10}{|l|}{ SB x PU Interaction } \\
\hline Within NegNT & & $\begin{array}{l}.28 \\
(.08)\end{array}$ & $.13, .43$ & .38 & .0003 & $\begin{array}{l}.05 \\
(.08)\end{array}$ & $\begin{array}{c}-.12 \\
.21\end{array}$ & .06 & .556 \\
\hline Within NegYT & & $\begin{array}{l}-.31 \\
(.22)\end{array}$ & $\begin{array}{l}-.74 \\
.13\end{array}$ & .41 & .168 & $\begin{array}{l}-.03 \\
(.20)\end{array}$ & $\begin{array}{c}-.43 \\
.37\end{array}$ & .04 & .873 \\
\hline Within PLHIV & & $\begin{array}{l}.28 \\
(.25)\end{array}$ & $\begin{array}{l}-.21 \\
.77\end{array}$ & .37 & .258 & $\begin{array}{l}.02 \\
(.22)\end{array}$ & $\begin{array}{c}-.42 \\
.46\end{array}$ & .03 & .929 \\
\hline Within DND & & $\begin{array}{l}.44 \\
(.25)\end{array}$ & $\begin{array}{l}-.05 \\
.92\end{array}$ & .58 & .076 & $\begin{array}{l}.26 \\
(.22)\end{array}$ & $\begin{array}{c}-.18 \\
.70\end{array}$ & .35 & .249 \\
\hline \multicolumn{10}{|l|}{$\begin{array}{l}\text { SB x PU x HPS } \\
\text { Interaction }\end{array}$} \\
\hline & $\begin{array}{c}\text { NegYT- } \\
\quad \text { NegNT }\end{array}$ & $\begin{array}{l}-.59 \\
(.23)\end{array}$ & $\begin{array}{c}-1.1,- \\
.13\end{array}$ & -.78 & .013 & $\begin{array}{l}-.08 \\
(.21)\end{array}$ & $\begin{array}{c}-.49, \\
.34\end{array}$ & .11 & .709 \\
\hline & $\begin{array}{r}\text { PLHIV- } \\
\quad \text { NegNT }\end{array}$ & $\begin{array}{l}-.003 \\
(.26)\end{array}$ & $\begin{array}{c}-.51 \\
.50\end{array}$ & .004 & .991 & $\begin{array}{l}-.03 \\
(.23)\end{array}$ & $\begin{array}{c}-.48 \\
.43\end{array}$ & .04 & .909 \\
\hline & $D N D-N e g N T$ & $\begin{array}{l}.16 \\
(.26)\end{array}$ & $\begin{array}{l}-.35 \\
.66\end{array}$ & .21 & .545 & $\begin{array}{l}.21 \\
(.23)\end{array}$ & $\begin{array}{l}-.24 \\
.67\end{array}$ & .29 & .359 \\
\hline
\end{tabular}

Note: Due to the large potential number of comparisons, we focus the table on the simple effect of HIV/PrEP status, the sexual behavior x PrEP use interaction within each of those groups, and the three-way interaction. NegNT = HIV negative, not taking PrEP; NegYT = HIV negative, yes taking PrEP; PLHIV = people living with HIV; DND = Did not disclose. Marginal and significant results are highlighted to aid in interpretation. 